\title{
Role of Lanthanide-Ligand bonding in the magnetization relaxation of mononuclear single-ion magnets: A case study on Pyrazole and Carbene ligated $\mathrm{Ln}^{\mathrm{III}}(\mathrm{Ln}=\mathrm{Tb}, \mathrm{Dy}, \mathrm{Ho}, \mathrm{Er})$ complexes
}

\author{
TULIKA GUPTA, GUNASEKARAN VELMURUGAN, THAYALAN RAJESHKUMAR and \\ GOPALAN RAJARAMAN* \\ Department of Chemistry, Indian Institute of Technology Bombay, Powai, Mumbai 400 076, India \\ e-mail: rajaraman@chem.iitb.ac.in
}

MS received 20 April 2016; revised 24 June 2016; accepted 6 July 2016

\begin{abstract}
A $b$ initio CASSCF+RASSI-SO+SINGLE_ANISO and DFT based NBO and QTAIM investigations were carried out on a series of trigonal prismatic $\mathrm{M}\left(\mathrm{Bc}{ }^{\mathrm{Me}}\right)_{3}\left(\mathrm{M}=\mathrm{Tb}(\mathbf{1}), \mathrm{Dy}(\mathbf{2}), \mathrm{Ho}(\mathbf{3}), \mathrm{Er}(\mathbf{4}),\left[\mathrm{Bc}^{\mathrm{Me}}\right]^{-}=\right.$ dihydrobis(methylimidazolyl)borate) and $\mathrm{M}\left(\mathrm{Bp}^{\mathrm{Me}}\right)_{3}\left(\mathrm{M}=\mathrm{Tb}(\mathbf{1 a}), \operatorname{Dy}(\mathbf{2 a}), \operatorname{Ho}(\mathbf{3 a}), \operatorname{Er}(\mathbf{4 a})\left[\mathrm{Bp}^{\mathrm{Me}}\right]^{-}=\right.$dihydrobis(methypyrazolyl)borate) complexes to ascertain the anisotropic variations of these two ligand field environments and the influence of Lanthanide-ligand bonding on the magnetic anisotropy. Among all the complexes studied, only $\mathbf{1}$ and $\mathbf{2}$ show large $\mathrm{U}_{\text {cal }}$ (computed energy barrier for magnetization reorientation) values of 256.4 and $268.5 \mathrm{~cm}^{-1}$, respectively and this is in accordance with experiment. Experimentally only frequency dependent $\chi$ " tails are observed for complex $1 \mathrm{a}$ and our calculation predicts a large $\mathrm{U}_{\mathrm{cal}}$ of $229.4 \mathrm{~cm}^{-1}$ for this molecule. Besides these, none of the complexes $(\mathbf{3}, \mathbf{4}, \mathbf{2} \mathbf{a}, \mathbf{3} \mathbf{a}$ and $\mathbf{4 a})$ computed to possess large energy barrier and this is affirmed by the experiments. These observed differences in the magnetic properties are correlated to the Ln-Ligand bonding. Our calculations transpire comparatively improved Single-Ion Magnet (SIM) behaviour for carbene analogues due to the more axially compressed trigonal prismatic ligand environment. Furthermore, our detailed Mulliken charge, spin density, NBO and Wiberg bond analysis implied stronger $\mathrm{Ln}^{\cdots} \mathrm{H}-\mathrm{BH}$ agostic interaction for pyrazole analogues. Further, QTAIM analysis reveals the physical nature of coordination, covalent, and fine details of the agostic interactions in all the eight complexes studied. Quite interestingly, for the first time, using the Laplacian density, we are able to quantify the prolate and oblate nature of the electron clouds in lanthanides and this is expected to have a far reaching outcome beyond the examples studied.
\end{abstract}

Keywords. Lanthanides; magnetic anisotropy; ligand field environment; QTAIM and wiberg bond index analysis; single ion magnets.

\section{Introduction}

Since last two decades, lanthanide $\left\{\mathrm{Ln}^{\mathrm{III}}\right\}^{1-13}$ containing complexes have become ubiquitous in the field of single molecule magnets (SMMs) having potential application in magnetic data storage. ${ }^{14-17}$ This is essentially due to their inherently large single-ion anisotropy arising from their deeply buried $4 \mathrm{f}$ orbitals, large unquenched orbital angular momentum and large number of unpaired electrons. $\mathrm{Ln}^{\mathrm{III}}$ SMMs are preferred over their corresponding transition metal analogues as former result in larger effective energy barrier $^{3,4}$ for magnetization reorientation $\left(\mathrm{U}_{\text {eff }}\right)$ upon Arrhenius fitting of the temperature dependence of relaxation time. Due to the large single-ion anisotropy of $4 \mathrm{f}$ metal

\footnotetext{
*For correspondence

Celebrating 100 years of Lewis Chemical Bond
}

ions, even systems containing only one spin carrier $\left\{\mathrm{Ln}^{\mathrm{III}}\right\}$ within a molecule are exhibiting magnetization blockade and these are termed as Single Ion Magnets (SIMs). ${ }^{5,18-34}$ Importance of magnetic anisotropy in the area of SMMs and ease of fine tuning it in mononuclear complexes has made the role of SIMs indispensable. Despite the tremendous progress in the area of SMMs and SIMs, they function only at very low temperatures (below liquid helium temperatures). Hence, in the quest of improved SIM characteristics, fine tuning of magnetic anisotropy and search/design of SIMs which are functional at room temperature ${ }^{35,36}$ is imperative.

Lack of uniaxiality/presence of perturbations, i.e., transverse magnetic field led to mixing of opposite angular momentum projection, and this subsequently results in enhanced Quantum Tunneling of Magnetization (QTM) as well as poor SMM characteristics. Crystal field $^{23,24,27,37-44}$ of the surrounding ligands essentially 
dictate the magnetic properties in SIMs entailing the need to fine tune ligand field strength towards novel targeted design of SIMs. Alongside, coordination number ${ }^{1,45-48}$ around the metal ion, coordination geometry/environment, ${ }^{49}$ nature of the coordinated ligand and local point group symmetry need to be targeted simultaneously in order to achieve large $U_{\text {eff }}$ values. The control of magnetic properties via structural, electronic feature as well as ligand field surroundings complicates the spin dynamics in SIMs and necessitates profound understanding of these issues. Recently, ${ }^{50}$ crucial role of $4 \mathrm{f}$ electron density distributions of $\mathrm{Ln}^{\mathrm{III}}$ ions have been proposed in an electrostatic manner to synthesize complexes towards stabilization of higher angular momentum energy levels. This explicitly suggests use of axial ligand field to stabilize largest angular momentum projections for oblate ions $\left\{\mathrm{Tb}^{\mathrm{III}}\right.$, Dy ${ }^{\mathrm{III}}$ and $\mathrm{Ho}^{\mathrm{III}}$ \}and equatorial ligand field is preferred in prolate ions $\left\{\mathrm{Er}^{\mathrm{III}}\right.$ and $\left.\mathrm{Yb}^{\mathrm{III}}\right\}$. Hence, $4 \mathrm{f}$ electron density, corresponding crystal field parameters, magnitude of angular momentum also need to be modulated simultaneously in order to gain deeper insights into the magnetic anisotropic properties in $\mathrm{Ln}^{\mathrm{III}}$ based SIMs. ${ }^{50}$

Extensive experimental studies (Inelastic Neutron Scattering, HF-EPR, Angular Overlap Model) $)^{39,51-54}$ have been utilized to probe magnetic anisotropy, but sufficient knowledge about the directions of local anisotropy axes could not be obtained. Fragment quantum chemistry calculations can be a good alternative in this regard as it accounts for spin-orbit coupling non-perturbatively. It enables determination of orientation of local anisotropy axis of the metal ion through estimation of g-tensors of the ground multiplet of the $\mathrm{Ln}^{\mathrm{III}}$ ions. CASSCF+RASSI-SO+SINGLE_ANISO methodology has proved its aptness in such kind of studies and verified experimentally observed magnetic data nicely. ${ }^{23,41,43,48,49,55-78}$

Recently, ${ }^{79}$ Long et al., reported isostructural series of trigonal prismatic $\mathrm{M}\left(\mathrm{Bc}^{\mathrm{Me}}\right)_{3}(\mathrm{M}=\mathrm{Tb}(\mathbf{1}), \mathrm{Dy}(\mathbf{2}), \mathrm{Ho}(\mathbf{3})$, $\operatorname{Er}(\mathbf{4}),\left[\mathrm{Bc}^{\mathrm{Me}}\right]^{-}=$dihydrobis(methylimidazolyl)borate) and $\mathrm{M}\left(\mathrm{Bp}^{\mathrm{Me}}\right)_{3}(\mathrm{M}=\mathrm{Tb}(\mathbf{1 a}), \operatorname{Dy}(\mathbf{2 a}), \operatorname{Ho}(\mathbf{3 a}), \operatorname{Er}(\mathbf{4 a})$ $\left[\mathrm{Bp}^{\mathrm{Me}}\right]^{-}=$dihydrobis(methypyrazolyl)borate) complexes. Concrete experimental magnetic techniques showed slower relaxation of magnetization for $\mathrm{N}$-heterocyclic carbenes $\left\{\mathrm{M}\left(\mathrm{Bc}^{\mathrm{Me}}\right)_{3}\right\}$-based lanthanides as compared to their isomeric pyrazole $\left\{\mathrm{M}\left(\mathrm{Bp}^{\mathrm{Me}}\right)_{3}\right\}$ ligands-based lanthanide analogues, suggesting better SIM behavior for the former. However, only for complexes $\mathrm{Tb}\left(\mathrm{Bc}^{\mathrm{Me}}\right)_{3}$ (1) and $\mathrm{Dy}\left(\mathrm{Bc}^{\mathrm{Me}}\right)_{3}(\mathbf{2})$, frequency as well as temperature dependence of $\chi$ " component of magnetic susceptibility was detected. Complexes $\mathbf{1}$ and $\mathbf{2}$ show relaxation of magnetization with $U_{\text {eff }}$ values of $44.8 \mathrm{~cm}^{-1}$ (Yttrium diluted sample showed $45.2 \mathrm{~cm}^{-1}$ ) and $32.8 \mathrm{~cm}^{-1}$
(Yttrium diluted sample showed $33.6 \mathrm{~cm}^{-1}$ ), respectively, under an applied dc magnetic field of 1500 Oe (field induced SIM, f-SIM behaviour). ${ }^{79}$ On the other hand, only high frequency $\chi$ " tails are experimentally observed for complexes 1a and $\mathbf{2 a}$ at an applied dc magnetic field of 1250 Oe with small $U_{\text {eff }}$ of $21 \mathrm{~cm}^{-1}$ for 1a. ${ }^{79}$ Such change in magnetic behavior upon changing the number of $4 \mathrm{f}$ electrons has spurred our interest towards explicit analysis of these complexes and the nature of Ln-Ligand bonding. Therefore, here we have performed vigorous post-Hartree-Fock $a b$ initio and DFT calculations on these eight complexes with an aim to answer the following intriguing questions: i) What are the origins of different energy barrier for magnetization reorientations in carbene- and pyrazole ligated complexes? ii) What is the mechanism of relaxation in these sets of complexes? iii) How structure and bonding features influence the magnetization blockade (Table 1)?

\section{Computational}

MOLCAS $8.0^{80-86}$ suite has been employed to perform post-Hartree-Fock $a b$ initio calculations. Spinfree wave functions were generated using complete active space self-consistent field (CASSCF) method. These multi-configurational wave functions have been used as input states to account for spin-orbit coupling via Restricted Active Space Spin State InteractionSpin Orbit (RASSI-SO) methodology. ${ }^{86,87}$ The resultant energies of the multiplets were used for the calculation of the anisotropic magnetic properties and g-tensors of the lowest state using a specially designed routine SINGLE_ANISO. ${ }^{88}$ We have employed [ANORCC...7s6p4d2f1g.] basis set for $\operatorname{Ln}^{\mathrm{III}}\left\{\mathrm{Ln}^{\mathrm{III}}=\mathrm{Tb}\right.$, Dy, Ho, Er\}, [ANO-RCC...3s2p.] basis set for N,O,C and $\mathrm{B}$, and [ANO-RCC...2s.] basis set for $\mathrm{H}$ throughout our calculations. These ANO-RCC basis sets were adopted from ANO-RCC basis library included in MOLCAS 8.0 suite. The active space of $(8,7)$ is used for $\mathrm{Tb}\left(\mathrm{Bc}^{\mathrm{Me}}\right)_{3}$ (1) and $\mathrm{Tb}\left(\mathrm{Bp}^{\mathrm{Me}}\right)_{3}$ (1a) complexes. In the Configurational Interaction (CI) procedure, 7 septets, 140 quintets and 195 triplets are considered. The singlet states were not included due to computational limitations. In the RASSI module, 7 septets, 105 quintets and 112 triplets are mixed by spin-orbit coupling within the energy window of about $40,000 \mathrm{~cm}^{-1}$. The active space $(9,7)$ is adopted for $\mathrm{Dy}\left(\mathrm{Bc}^{\mathrm{Me}}\right)_{3}$ (2) and $\mathrm{Dy}\left(\mathrm{Bp}^{\mathrm{Me}}\right)_{3}$ (2a) complexes. Here, in the CI procedure, 21 sextets were considered and this was only mixed by spin-orbit coupling as it has been found to be robust for computing the $g$ tensors for Dy ${ }^{\mathrm{III}}$ ions. The active space $(10,7)$ is used for $\mathrm{Ho}\left(\mathrm{Bc}^{\mathrm{Me}}\right)_{3}(\mathbf{3})$ and $\mathrm{Ho}\left(\mathrm{Bp}^{\mathrm{Me}}\right)_{3}$ (3a) complexes. In 
Table 1. Calculated energy spectrum, g-tensors, relative energies and angles $(\theta)$ of the principal anisotropy axes of first excited states with respect to the ground state for ground and first excited Kramers (for 2, 2a, 4, 4a) and pseudo doublets (for $\mathbf{1}, \mathbf{1 a}, \mathbf{3}$ and $\mathbf{3 a}$ ) in $\mathbf{1 - 4}$ and $\mathbf{1 a - 4 a .}$

\begin{tabular}{|c|c|c|c|c|c|c|c|c|}
\hline Ground multiplet & 1 & 2 & 3 & 4 & $1 \mathrm{a}$ & $\mathbf{2 a}$ & $3 a$ & $4 \mathrm{a}$ \\
\hline$g_{x}$ & 0 & 0.07 & 9.64 & 0.58 & 0 & 0.06 & 0 & 9.53 \\
\hline $\mathrm{g}_{\mathrm{y}}$ & 0 & 0.09 & 9.33 & 1.73 & 0 & 0.08 & 0 & 9.61 \\
\hline $\mathrm{g}_{\mathrm{z}}$ & 17.93 & 19.91 & 1.08 & 3.66 & 17.92 & 19.91 & 16.92 & 0.81 \\
\hline Energy $\left(\mathrm{cm}^{-1}\right)$ & 0.0 and 0.02 & 0.0 & 0.0 and 0.04 & 0.0 & 0.0 and 0.05 & 0.0 & 0.0 and 0.07 & 0.0 \\
\hline $1^{\text {st }}$ excited multiplet & 1 & 2 & 3 & 4 & $1 \mathbf{a}$ & $\mathbf{2 a}$ & $3 a$ & $4 a$ \\
\hline$g_{x}$ & 0 & 0.01 & 0.08 & 0.51 & 0 & 0.24 & 0 & 0.35 \\
\hline $\mathrm{g}_{\mathrm{y}}$ & 0 & 0.18 & 0.24 & 0.70 & 0 & 0.38 & 0 & 0.68 \\
\hline $\mathrm{g}_{\mathrm{z}}$ & 14.65 & 17.31 & 3.17 & 3.77 & 14.66 & 17.26 & 14.37 & 2.14 \\
\hline Energy $\left(\mathrm{cm}^{-1}\right)$ & 256.36 and 256.39 & 7.27 & 9.01 and 12.05 & 23.29 & 229.39 and 229.44 & 23.19 & 13.08 and 25.43 & 5.63 \\
\hline $\operatorname{angle}\left({ }^{\circ}\right)$ & 0.01 & 2.73 & 0.01 & 0.71 & 0.01 & 0.35 & 0.34 & 8.28 \\
\hline $\mathrm{U}_{\mathrm{cal}}\left(\mathrm{cm}^{-1}\right)$ & 256.36 & $268.50 *$ & 9.01 & 23.29 & 229.39 & 23.19 & 13.08 & 5.63 \\
\hline $\mathrm{U}_{\mathrm{eff}}\left(\mathrm{cm}^{-1}\right)$ & $44.8(45.2)$ & $32.8(33.6)$ & - & - & 21 & - & - & - \\
\hline
\end{tabular}

*Barrier with respect to the fourth excited $\mathrm{KD}$; Values within bracket in $\mathrm{U}_{\text {eff }}$ row represent experimentally estimated energy barrier for Yttrium diluted samples.

the configurational Interaction (CI) procedure, 35 quintets, 210 triplets and 196 singlets are considered. In the RASSI module, 35 quintets, 118 triplets and 76 singlets and 30 quintets, 107 triplets and 38 singlets for $\mathbf{3}$ and 7 respectively are mixed by spin-orbit coupling within the energy window of about $40,000 \mathrm{~cm}^{-1}$. The active space $(11,7)$ is adopted for $\operatorname{Er}\left(\mathrm{Bc}^{\mathrm{Me}}\right)_{3}(\mathbf{4})$ and $\operatorname{Er}\left(\mathrm{Bp}^{\mathrm{Me}}\right)_{3}$ (4a) complexes. In the configurational Interaction (CI) procedure, 35 quartets and 112 doublets are considered. In the RASSI module, 35 quartets and 112 doublets for both the Er ${ }^{\mathrm{III}}$ complexes are mixed by spin-orbit coupling within the energy window of about $40,000 \mathrm{~cm}^{-1}$. Mulliken charges and the spin densities have been computed using DFT calculations employing Gaussian $09^{89}$ suite. Here we have employed the B3LYP functional, along with the $\mathrm{CSDZ}^{90}$ basis set for the $\mathrm{Ln}^{\mathrm{III}}$ ion and the Ahlrichs triple- $\zeta^{91}$ basis set (TZV) has been employed for the rest of the atoms.

The wave function for use in quantum theory of atoms in molecules (QTAIM) analysis were generated from single point calculation using hybrid B3LYP functional ${ }^{92-94}$ with a combination of $\mathrm{CSDZ}^{90} \mathrm{ECP}$ on Tb, Dy, Ho, Er and TZV Ahlrichs triple- $\zeta$ basis set on other atoms as implemented in the Gaussian 09 suite $^{89}$ of programs. Further, the quantum theory of atoms in molecule (QTAIM) was applied to depict the topological properties of the chosen complexes. To better understand the nature of the interaction of the Ln atom with others, we have used the Baders Atoms in Molecules theory. ${ }^{95}$ In this theory, Bader and co-workers characterize bonding and non-bonding interactions of atoms in terms of topological properties such as electron density $\rho(r)$, Laplacian of the electron density $\mathrm{L}(r)$, potential energy density $\mathrm{V}(r)$, kinetic energy density $\mathrm{H}(r)$ and a potential energy to the Lagrangian kinetic energy ratio $(\mid \mathrm{V}(\mathrm{r}) / \mathrm{G}(\mathrm{r})) \mid$. For instance, the presence of a $(3,-1)$ critical point in QTAIM topography represents a chemical bond between two atoms and are called as the bond critical points (BCPs) where the shared electron density reaches a minimum, whereas a critical point with $(3,+1)$ and $(3,+3)$ signatures identify a ring structure (RCP) and cage critical point (CCP) in the molecular system. The $\rho(r)$ values at the BCPs are related to the strength of the bonds. ${ }^{96}$ In this study, QTAIM calculations are performed at B3LYP/CSDZ level using AIM2000 package. ${ }^{97}$

\section{Results and Discussion}

We have chosen eight isostructural and isomeric complexes 1-4 and 1a-4a for our study. All the complexes comprise six coordinate $\mathrm{Tb}^{\mathrm{III}}$, $\mathrm{Dy}^{\mathrm{III}}, \mathrm{Ho}^{\mathrm{III}}$ and $\mathrm{Er}^{\mathrm{III}}$ in tricapped trigonal prismatic coordination environment surrounded by three pyrazolate ligands in complexes 1a-4a and three N-heterocyclic carbene ligands in complexes 1-4. Among the lanthanide family, Dy ${ }^{\mathrm{III}}$ ion has indisputably led to the largest number of pure SIMs. This is ascribable to the reduced QTM of these systems compared to other lanthanide ions owing to its large magnetic moment and odd electron configuration. Here, we begin our discussion with single-ion magnetic behaviour in all the complexes followed by cross comparison between lanthanide complexes.

\subsection{Single-ion anisotropy studies on complexes 1 and $1 \mathbf{a}$}

The energy spectrum for thirteen energy states (six pseudo-doublets and one singlet) of the ground ${ }^{7} \mathrm{~F}_{6}$ 
multiplet for the $\mathrm{Tb}^{\mathrm{III}}$ ion and g-tensors of ground state in compounds 1 and 1a are shown in the Supplementary Information (SI), with the excited states lying at $2400 \mathrm{~cm}^{-1}$. As expected for the non-Kramers ion, all the pseudo-doublets in complexes $\mathbf{1}$ and $\mathbf{1 a}$ are pure Ising in nature. Ground pseudo-doublet for $\mathbf{1}$ and $\mathbf{1 a}$ possesses $\mathrm{g}_{\mathrm{z}}$ value of 17.93 and 17.92 (see ground state $g_{z}$ orientation in Figures 1a and $1 b$ ), respectively, approaching that expected for pure $\mathrm{m}_{\mathrm{J}}= \pm 6$ state of $\mathrm{g}_{\mathrm{z}} \sim 18$. See Tables S3 and S4 in Supplementary Information. Tunnel splitting $\left(\Delta_{\text {tun }}\right)$ within the ground multiplets is considerable for both the complexes $(0.02$ and $0.05 \mathrm{~cm}^{-1}$ for $\mathbf{1}$ and $\mathbf{1 a}$, respectively; larger than the cut-off value of $10^{-5} \mathrm{~cm}^{-1}$ (Table 1)) suggesting absence of magnetic bistability. This precludes zerofield SIM behaviour for both the complexes. However, application of dc field enhances the ground-first excited level gap posing probable SIM characteristics on both the compounds by quenching QTM probability. Our calculations affirm tunnel splitting of 0.03 and 0.04 $\mathrm{cm}^{-1}$, respectively, for $\mathbf{1}$ and $\mathbf{1 a}$ in their corresponding first excited pseudo-doublets. This outlines calculated energy barrier $\left(\mathrm{U}_{\text {cal }}\right)$ to be 256.4 and $229.4 \mathrm{~cm}^{-1}$ for $\mathbf{1}$ and $\mathbf{1 a}$ (Table 1), respectively to promote relaxation via this level. This represents both $\mathbf{1}$ and $\mathbf{1 a}$ to be SIM. In complex $\mathbf{1}$, our calculations overestimate the experimentally observed $U_{\text {eff }}$ value of $44.8(45.2) \mathrm{cm}^{-1}$ and this can be ascribed to the lack of consideration of intermolecular interaction and zero-field QTM in our calculations.

However, though complex 1a shows large $\mathrm{U}_{\text {cal }}$ of $229.4 \mathrm{~cm}^{-1}$, frequency tails ( $\chi$ ") at field of $1250 \mathrm{Oe}$

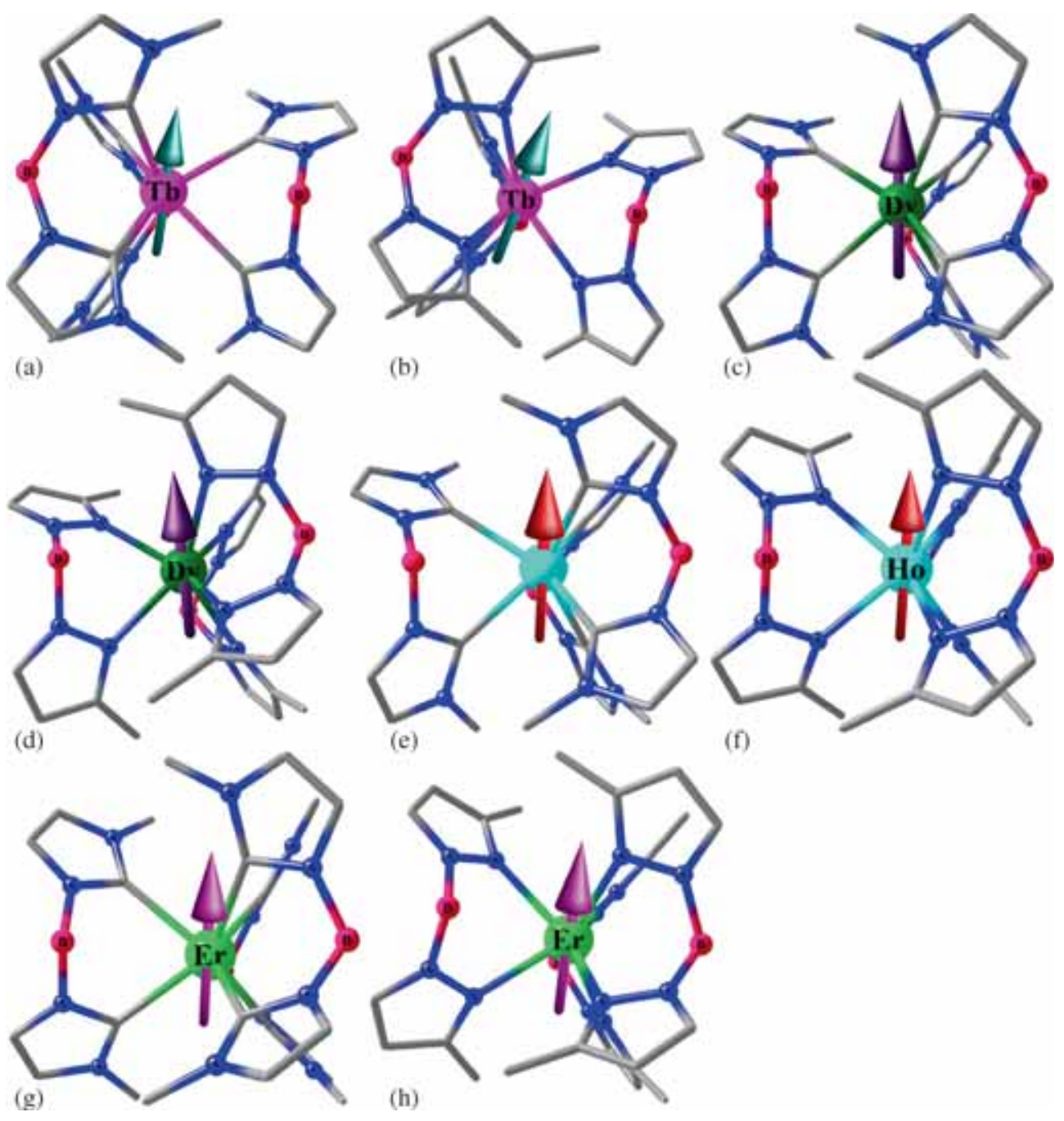

Figure 1. Ab initio computed orientation of $\mathrm{g}_{\mathrm{z}}$-tensor for ground state $\mathrm{KD}$ in complexes. (a) 1, (b) 1a, (c) 2, (d) 2a (e) 3, (f) 3a, (g) 4 and (h) 4a, as shown with their crystal structures $\left\{\mathrm{M}\left(\mathrm{Bc}^{\mathrm{Me}}\right)_{3}\left(\mathrm{M}=\mathrm{Tb}(\mathbf{1}), \mathrm{Dy}(\mathbf{2}), \mathrm{Ho}(\mathbf{3}), \mathrm{Er}(\mathbf{4}),\left[\mathrm{Bc}^{\mathrm{Me}}\right]^{-}=\right.\right.$dihydrobis(methylimidazolyl)borate) and $\mathrm{M}\left(\mathrm{Bp}^{\mathrm{Me}}\right)_{3}(\mathrm{M}=\mathrm{Tb}(\mathbf{1 a}), \operatorname{Dy}(\mathbf{2 a}), \operatorname{Ho}(\mathbf{3 a}), \operatorname{Er}(\mathbf{4 a})$, $\left[\mathrm{Bp}^{\mathrm{Me}}\right]^{-}=$dihydrobis(methypyrazolyl)borate) $\}$. Color scheme: Tb: red, Dy: dark green, Ho: sky blue, Er: light green, O: red, N: blue, C: grey. $\mathrm{H}$ atoms have been removed for clarity. 
was experimentally observed leading to the estimation of $U_{\text {eff }}$ as $21 \mathrm{~cm}^{-1}$. Our wave function analysis reveals ground state as a admixture of $70 \% \mid \pm 6>$ and small contributions from other $\mathrm{m}_{\mathrm{J}}$ levels for $\mathbf{1}$ and $\mathbf{1 a}$. Ground state axial crystal field parameters are much larger $\left(B_{2}^{0}=5.47\right.$ and 4.75 for $\mathbf{1}$ and $\mathbf{1 a}$ respectively) than the corresponding non-axial terms $\left(B_{2}^{-1,+1}\right)$ (see Table S9 in SI). This accounts for the pure Ising nature, resulting from the non-Kramer $\mathrm{Tb}^{\mathrm{III}}$ ion in complexes $\mathbf{1}$ and 1a. For both the compounds, $g_{z}$ orientation intersects through the negatively charged three ligands in order to encounter least electrostatic repulsion (Figures 1a and $1 \mathrm{~b}$ ). Our computed data is further substantiated by nice agreement between calculated and experimental $\chi_{\mathrm{m}} \mathrm{T}$ vs $\mathrm{T}$ plots (Figures $3 \mathrm{a}$ and $3 \mathrm{~b}$ ).

\subsection{Single-ion anisotropy studies on complexes $\mathbf{2}$ and $\mathbf{2 a}$}

The energy spectrum for eight Kramers doublets of the ground ${ }^{6} \mathrm{H}_{15 / 2}$ multiplet for the Dy ${ }^{\mathrm{III}}$ ion and g-tensors of ground state in compound $\mathbf{2}$ and $\mathbf{2 a}$ are shown in the Supplementary Information, with the excited states lying at $3000 \mathrm{~cm}^{-1}$. In $\mathbf{2}$ and $\mathbf{2 a}$, the ground state (GS) Kramers doublet (KD) shows almost Ising type anisotropy with $\mathrm{g}_{\mathrm{xy}}<0.5$ (Tables $\mathrm{S} 1$ and S2 in Supplementary Information (Table 1)) i.e., $\mathrm{g}_{\mathrm{z}}=19.91$ i.e., (see ground state $g_{z}$ orientation in Figures $1 c$ and $1 d$ ) close to that expected for a pure $\mathrm{m}_{\mathrm{J}}= \pm 15 / 2$ state of $\mathrm{g}_{\mathrm{z}} \sim 20$. It is worthy to note that, all the computed g-tensors correspond to an effective spin $\tilde{S}=1 / 2$ of the KDs. For 2, main anisotropic g-tensor $\left(g_{z}\right)$ lies at lower angles $\left(<3^{\circ}\right)$ upto fourth excited KD. This opens up probabilities of magnetic relaxation via higher excited multiplets resulting in larger energy barrier for magnetization reorientation. It is notable that, transverse components of the energy multiplets are negligible upto third excited KD; $\mathrm{g}_{\mathrm{xy}}<0.5$ and it becomes very prominent in fourth excited $\mathrm{KD}\left(\mathrm{g}_{\mathrm{x}}=5.1 ; \mathrm{g}_{\mathrm{y}}=\right.$ $5.3, \mathrm{~g}_{\mathrm{z}}=8.0$ ). We have further analysed the relaxation mechanism which can occur via three pathways: a) QTM between the ground KDs owing to substantial transverse anisotropy of ground KDs; b) Orbach/Raman process to induce relaxation via excited KDs which is essentially controlled by non-collinearity of $g_{z}$ axis; c) thermally assisted-QTM (TA-QTM) within excited KDs resulting due to non-Ising nature of excited KDs. In qualitative $a b$ initio computed relaxation mechanism, the KDs are arranged in accordance with their magnetic moments. The numbers at each arrows (solid, dashed and dotted) connecting any two energy states correlate to the matrix elements of the transition magnetic moments between the respective energy levels. As the ground state is almost pure Ising type due to negligible transverse anisotropy, QTM pathway is least effective via this state as reflected in computed magnetic moment of $0.03 \mu_{\mathrm{B}}$. We would like to note here that matrix element connecting same multiplets of opposite directional magnetization having a value $>10^{-1} \mu_{\mathrm{B}}$ along with substantial transverse component $\left(\mathrm{g}_{\mathrm{xy}} \sim 4\right)$ promotes relaxation via that particular state. ${ }^{14 \mathrm{~h}}$ Similar trend of less efficient TA-QTM within excited states was evident $\left(\sim 0.05 \mu_{\mathrm{B}}\right)$ upto third excited $\mathrm{KD}$ due to negligible transverse anisotropy. Although pronounced magnetic moment corresponding to Orbach/Raman relaxation upto third excited $\mathrm{KD}\left(\sim 3 \mu_{\mathrm{B}}\right)$ was computed, lower angle of the $g_{z}$ alignment of excited KDs (upto third) with respect to ground $\mathrm{KD}$ and small transverse components deters relaxation via these states. Fourth excited $\mathrm{KD}$ possesses huge transverse anisotropy and this was corroborated by substantial TA-QTM pathway via this state $\left(1.76 \mu_{\mathrm{B}}\right)$ and a significant Orbach relaxation pathway $\left(3.09 \mu_{\mathrm{B}}\right)$. This essentially outlines the calculated energy barrier $\left(\mathrm{U}_{\mathrm{cal}}\right)$ as $268.5 \mathrm{~cm}^{-1}$ (Figure 2a) with respect to the experimental $U_{\text {eff }}$ value $32.8(33.6) \mathrm{cm}^{-1}$ for complex 2 (Table 1). This large discrepancy between $\mathrm{U}_{\text {cal }}$ and $\mathrm{U}_{\text {eff }}$ values have been observed earlier and are attributed to, (i) QTM effects which are not incorporated in the $\mathrm{U}_{\text {cal }}$ estimates, (ii) intermolecular/hyperfine interactions, and (iii) other relaxation mechanism such as Raman process being operational. Ising nature of the ground state is also corroborated by negligible QTM $\left(0.02 \mu_{\mathrm{B}}\right)$ in complex $2 \mathrm{a}$ (Figure $\left.2 \mathrm{~b}\right)$. Now, complex 2a reveals huge transverse anisotropy $\left(\mathrm{g}_{\mathrm{xy}}>0.5 ; \mathrm{g}_{\mathrm{xy}}\right.$ $<4)$ in the first excited KD which is also reflected in pronounced TA-QTM $\left(0.10 \mu_{\mathrm{B}}\right)$. This outlines $\mathrm{U}_{\text {cal }}$ as $23.2 \mathrm{~cm}^{-1}$ which is in line with the experimentally observed high frequency tails ( $\chi$ ") at field of $1250 \mathrm{Oe}$ with no observed $U_{\text {eff }}$ values.

Our wavefunction analysis is affirmative of $I \pm$ $15 / 2>99 \% \mid \pm 15 / 2>$, as ground state KD for both the complexes. However, fourth excited KD which involves in determining energy barrier is admixture of $56 \% \mathrm{I} \pm$ $7 / 2>+18 \% \mid \pm 5 / 2>$ states in complex 2 . In complex 2a, first excited KD is pure $\mid \pm 13 / 2>$ : $94 \%$ I $13 / 2>$ state. Ground state axial crystal field parameters are much larger $\left(B_{2}^{0}=3.28\right.$ and 2.97 for 2 and 2a, respectively) than corresponding non-axial terms $\left(B_{2}^{-1,+1}\right)$ (Table S9 in SI). This suggests suppressed QTM within ground state for both the complexes reiterating our earlier statements. For both the compounds, $\mathrm{g}_{\mathrm{z}}$ orientation intersects through the negatively charged three ligands in order to encounter least electrostatic repulsion (see Figures 1c and 1d). Our computed data is further substantiated by nice agreement between calculated and experimental $\chi_{\mathrm{m}} \mathrm{T}$ vs $\mathrm{T}$ plots (Figures $3 \mathrm{c}$ and 3d). 

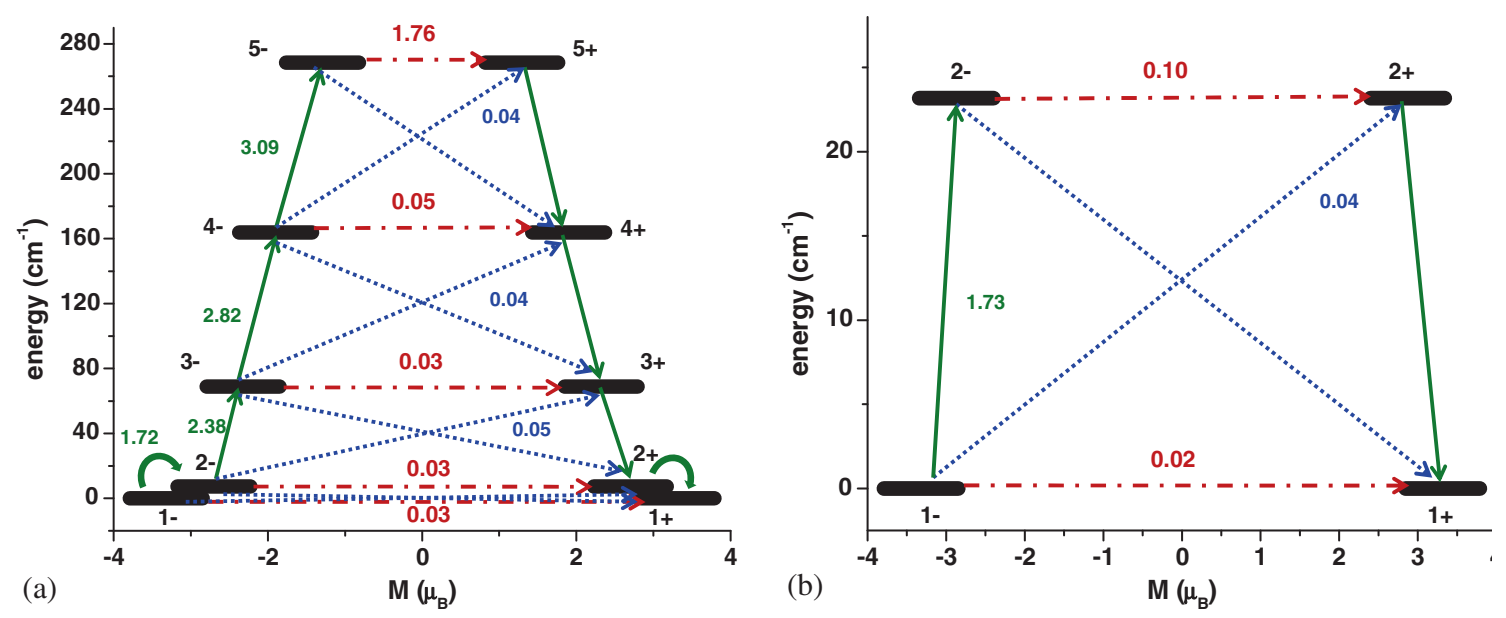

Figure 2. Ab initio calculated magnetization blocking barrier for complexes, (a) 2 and (b) 2a. The thick black line represent the Kramers doublets (KDs), as a function of magnetic moment. The blue dotted lines indicate the possible path for the Orbach process. The solid green arrows imply the most probable relaxation pathways for magnetization reversal. The dashed-dotted red lines correspond to the presence of QTM/TA-QTM between the connecting pairs. The numbers at each arrow are the mean absolute value for the corresponding matrix element of transition magnetic moment.
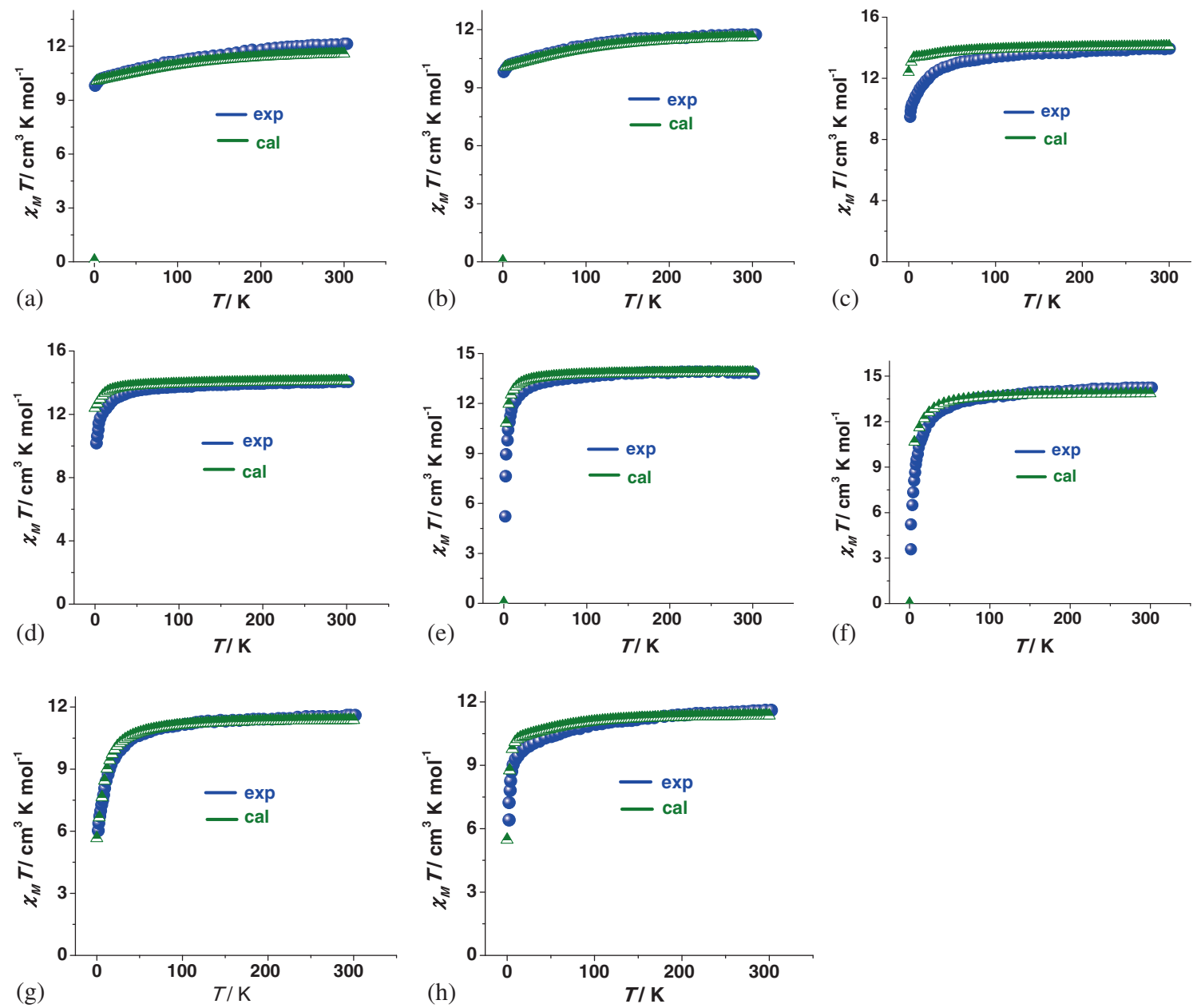

Figure 3. Experimental and ab initio calculated molar magnetic susceptibility plots for complexes; (a) 1, (b) 1a, (c) 2, (d) 2a, (e) 3, (f) 3a, (g) 4 and (h) 4a. Here, blue filled circles represent data extracted from experimental plots while half-filled-half-void green triangles correspond to $a b$ initio calculated molar magnetic susceptibilities. It is noteworthy, that intermolecular interaction $\mathrm{z} J$ is assumed to be zero in these calculations. 


\subsection{Single-ion anisotropy studies on complexes 3 and $\mathbf{3 a}$}

The energy spectrum for seventeen energy states (seven pseudo-doublets and three singlets) of the ground ${ }^{5} \mathrm{I}_{8}$ multiplet for the $\mathrm{Ho}^{\mathrm{III}}$ ion and g-tensors of ground state in compound $\mathbf{3}$ and $\mathbf{3} \mathbf{a}$ are shown in the Supplementary Information, with the excited states lying at $\sim 5200 \mathrm{~cm}^{-1}$. As expected for the non-Kramers ion, all the pseudo-doublets in complexes $\mathbf{3}$ and $\mathbf{3 a}$ are pure Ising in nature. Ground pseudo-doublet for $\mathbf{3}$ and 3a possesses $\mathrm{g}_{\mathrm{z}}$ of 17.10 and 16.92, respectively, (see ground state $\mathrm{g}_{\mathrm{z}}$ orientation in Figures 1e and 1f), resembles that expected for pure $\mathrm{m}_{\mathrm{J}}= \pm 7$ state of $\mathrm{g}_{\mathrm{z}} \sim 17.5$, (Tables S5 and S6 in SI) but far from the pure $\mathrm{m}_{\mathrm{J}}=$ \pm 8 state of $g_{z} \sim 20$. This is also corroborated by our computed wave function analysis which shows ground state composed of $70 \% \mid \pm 7>$ state with a small contributions from other $\mathrm{m}_{\mathrm{J}}$ levels for both the complexes. Tunnel splitting $\left(\Delta_{\text {tun }}\right)$ within the ground multiplets is considerably large for both the complexes $(0.04$ and $0.07 \mathrm{~cm}^{-1}$ for $\mathbf{3}$ and $\mathbf{3 a}$, respectively; larger than the cutoff value of $10^{-5} \mathrm{~cm}^{-1}$ (Table 1)) suggesting absence of magnetic bistability. This precludes zero-field SIM behaviour for both the complexes. However, application of dc field enhances the ground-first excited level gap posing probable SIM characteristics on both the compounds by suppressing the extent of QTM effects.

Our calculations yield tunnel splitting of 3.04 and $12.35 \mathrm{~cm}^{-1}$, respectively, for $\mathbf{3}$ and $\mathbf{3 a}$ in their corresponding first excited pseudo-doublets. This large tunnelling gap indicates relaxation via this state with $\mathrm{U}_{\text {cal }}$ value of 9.01 and $13.08 \mathrm{~cm}^{-1}$ for $\mathbf{3}$ and $\mathbf{3 a}$ (Table 1), respectively. Such small energy barrier value supports experimental observation of the absence of $\chi$ " peaks even in applied field conditions. This rules out the possibility of magnetic bistability as well as SIM behaviour. Ground state axial crystal field parameters are much larger $\left(B_{2}^{0}=1.00\right.$ and 0.93 for $\mathbf{3}$ and $\mathbf{3 a}$, respectively) than corresponding non-axial terms $\left(B_{2}^{-1,+1}\right)$ (Table S9 in SI). This accounts for the pure Ising nature resulting from the non-Kramer $\mathrm{Ho}^{\mathrm{III}}$ ion in complexes $\mathbf{3}$ and 3a. For both the compounds, $g_{z}$ orientation intersects through the negatively charged three ligands in order to encounter least electrostatic repulsion (Figures 1e and 1f). Our computed data is further substantiated by nice agreement between calculated and experimental $\chi_{\mathrm{m}} \mathrm{T}$ vs $\mathrm{T}$ plots (Figures $3 \mathrm{e}$ and $3 \mathrm{f}$ ).

\subsection{Single-ion anisotropy studies on complexes $\mathbf{4}$ and $\mathbf{4 a}$}

The energy spectrum for eight Kramers doublets of the ground ${ }^{4} \mathrm{I}_{15 / 2}$ multiplet for the $\mathrm{Er}^{\mathrm{III}}$ ion and g-tensors of ground state in compound $\mathbf{4}$ and $\mathbf{4 a}$ are shown in the Supplementary Information, with the excited states lying at $6600 \mathrm{~cm}^{-1}$. In 4 and $\mathbf{4 a}$, the ground state (GS) Kramers doublet (KD) contains substantial transverse anisotropy; i.e., $\mathrm{g}_{\mathrm{x}}=9.64, \mathrm{~g}_{\mathrm{y}}=9.33, \mathrm{~g}_{\mathrm{z}}=1.08$ and $\mathrm{g}_{\mathrm{x}}=9.53, \mathrm{~g}_{\mathrm{y}}=9.16, \mathrm{~g}_{\mathrm{z}}=0.81$ for $\mathbf{4}$ and 4a, respectively (see ground state $g_{z}$ orientation in Figures $1 \mathrm{~g}$ and $1 \mathrm{~h}$ ) (See Tables S7 and S8 in SI) (Table 1). This is also substantiated by stabilization of $\mathrm{m}_{\mathrm{J}}=| \pm 1 / 2>: 57 \%| \pm 1 / 2>$ and $\mathrm{m}_{\mathrm{J}}=\mid \pm$ $1 / 2>$ : $59 \% \mid \pm 1 / 2>$ for $\mathbf{4}$ and $\mathbf{4 a}$, respectively. Analysis on magnetic relaxation mechanism exhibits pronounced QTM of 3.16 and $3.11 \mu_{\mathrm{B}}$ in $\mathbf{4}$ and $\mathbf{4 a}$, respectively (see Figures $4 \mathrm{a}$ and $4 \mathrm{~b}$ ). This behaviour
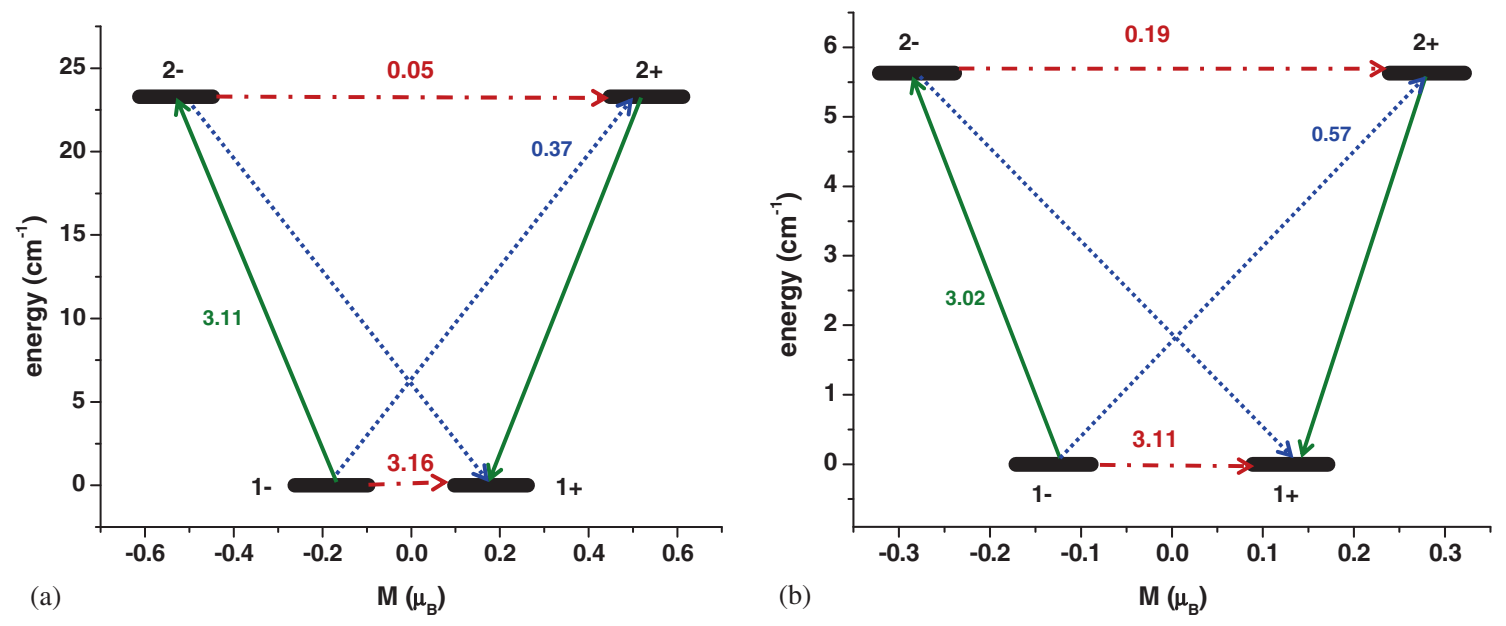

Figure 4. Ab initio calculated magnetization blocking barrier for complexes; (a) 4 and (b) $\mathbf{4 a}$. The thick black line represents the Kramers doublets (KDs), as a function of magnetic moment. The blue dotted lines indicate the possible path for the Orbach process. The solid green arrows imply the most probable relaxation pathways for magnetization reversal. The dashed-dotted red lines correspond to the presence of QTM/TA-QTM between the connecting pairs. The numbers at each arrow are the mean absolute value for the corresponding matrix element of transition magnetic moment. 
facilitates efficient QTM within the ground state precluding zero-field SIM behaviour in both of these complexes. However, on application of magnetic field, analysis of first excited KD becomes imperative. In complexes $\mathbf{4}$ and $\mathbf{4 a}$, even the first excited state is also associated with significant transverse components with very small value of $g_{z}$ (3.17 and 2.14 for 4 and $\mathbf{4 a}$, respectively). This indicates relaxation via this level with $\mathrm{U}_{\text {cal }}$ value of 23.3 and $5.6 \mathrm{~cm}^{-1}$ for 4 and 4a (Table 1), respectively. Such small value of barrier in complex 4a supports experimental absence of SIM behaviour nicely. Though for complex 4, the first excited level energy is comparable to that of complex 2a, significant $g_{x} / g_{y}$ component in conjunction with small $\mathrm{g}_{\mathrm{z}}$ component completely destroys the SIM behaviour even in the presence of applied dc magnetic field. Ground state axial crystal field parameters are marginally larger $\left(B_{2}^{0}=1.37\right.$ and 1.26 for $\mathbf{4}$ and $\mathbf{4 a}$, respectively) than corresponding non-axial terms $\left(B_{2}^{-1,+1}\right)$ and are of competing magnitude (see Table S9 in SI). This suggests probability of QTM within ground state for both the complexes reiterating our earlier statements. For both the compounds, $g_{z}$ orientation intersects through the negatively charged three ligands in order to encounter least electrostatic repulsion (Figures $1 \mathrm{~g}$ and $1 \mathrm{~h}$ ). Our computed data is further substantiated by nice agreement between calculated and experimental $\chi_{\mathrm{m}} \mathrm{T}$ vs T plots (Figures $3 \mathrm{~g}$ and $3 \mathrm{~h}$ ).

\subsection{Comparative analysis of single-ion anisotropy behaviour of complexes 1-4 and 1a-4a}

Our calculations reproduce the experimental SIM behaviour for complexes $1\left(\mathrm{U}_{\text {cal }}=256.36 \mathrm{~cm}^{-1}\right)$ and $2\left(\mathrm{U}_{\mathrm{cal}}=268.50 \mathrm{~cm}^{-1}\right)$. On the other hand, though computations predicted large energy barrier for magnetization reorientation for complex $\mathbf{1 a}\left(\mathrm{U}_{\mathrm{cal}}=229.39\right.$ $\mathrm{cm}^{-1}$ ), experimentally only high frequency tail ( $\chi$ ") was detected at 1250 Oe magnetic field with $U_{\text {eff }}$ of $21 \mathrm{~cm}^{-1}$. Calculated lower $\mathrm{U}_{\text {cal }}$ value for complex 2a $\left(\mathrm{U}_{\mathrm{cal}}=23.19 \mathrm{~cm}^{-1}\right)$ was in line with experimental high frequency tails ( $\chi$ ") at 1250 Oe. Rest of the four complexes containing $\mathrm{Ho}^{\mathrm{III}}$ (3 and 3a) and $\mathrm{Er}^{\mathrm{III}}$ (4 and 4a) ions lack SIM behaviour. Complexes with non-Kramers ion are found to be superior in producing larger barrier height for magnetization reversal. Axial alignment of the N-heterocyclic carbene as well as bis(pyrazolyl)borate ligand around $\mathrm{Ln}^{\mathrm{III}}$ ions is favourable for ions with oblate $4 \mathrm{f}$ electron density $\left(\mathrm{Tb}^{\mathrm{III}}\right.$, Dy ${ }^{\mathrm{III}}$ and $\mathrm{Ho}^{\mathrm{III}}$ ) while unfavourable for $\mathrm{Er}^{\mathrm{III}}$ ion with prolate electron density. Though Dy ${ }^{\mathrm{III}}$ and $\mathrm{Er}^{\mathrm{III}}$ ions possess similar $m_{\mathrm{J}}$ value of $15 / 2$, they differ in the shape of $4 \mathrm{f}$ electron density. This is evident through the stabilisation of $m_{J}= \pm 15 / 2$ and $1 / 2$ ground state
$\mathrm{KD}$ for complexes $\mathbf{2 / 2 \mathbf { a }}$ and $\mathbf{4 / 4 a}$, respectively. This can be ascribed to the unfavourable axial ligand position around $\mathrm{Er}^{\mathrm{III}}$ resulting in removal of SIM characteristics. N-heterocyclic carbene compounds are axially compressed trigonal prismatic structure as compared to that constituted by bis(pyrazolyl)borate ligand. This leads to comparatively better SIM characteristics for the N-heterocyclic-carbene analogues as compared to their corresponding bis(pyrazolyl)borate ligand analogues for all the complexes. Between complexes $\mathbf{2}$ and $\mathbf{2 a}$, observation of prominent transverse anisotropic components in later complex is affirmative of stronger crystal field mixing of the free-ion states in 2a. On the other hand, stronger crystal field mixing of the free-ion states and resultant poorly defined energy multiplets in complex $\mathbf{4 a}$ as compared to $\mathbf{4}$ has been manifested by distinctive deviation between ground and first excited anisotropy direction $\left(0.7^{\circ}\right.$ vs $8.3^{\circ}$ for $\mathbf{4}$ vs $\mathbf{4 a}$ ). Besides, it is notable that, larger deviation of first excited anisotropic direction with respect to the ground state is suggestive of low-symmetry ligand field environment. Hence, $\mathrm{U}_{\mathrm{cal}}$ value varies as complex $\mathbf{1} \approx \mathbf{2}>\mathbf{1 a}>\mathbf{2 a}$, revealing better behaviour for carbene analogues. For complexes $\mathbf{1} / \mathbf{1 a}, \mathrm{m}_{\mathrm{J}}= \pm 6$ has been stabilised as ground state in accordance with the expectation. However, for $\mathbf{3} \mathbf{3} \mathbf{3}, \mathrm{m}_{\mathrm{J}}= \pm 7$ has been stabilised as ground pseudo-doublet in contrary to the expected stabilisation of $\mathrm{m}_{\mathrm{J}}= \pm 8$ pseudo-doublet. This clearly demonstrates the comparatively lower symmetry ligand environment for $\mathrm{Ho}^{\mathrm{III}}$-based complexes as compared to their $\mathrm{Tb}^{\mathrm{III}}$ analogues. This was further corroborated by first excited tunnelling gap for 0.03 vs $3.04 \mathrm{~cm}^{-1}$ for 1 vs 3 and 0.04 vs $12.35 \mathrm{~cm}^{-1}$ for $\mathbf{1 a}$ vs 3a. Even within the similar ion analogues, tunnel splitting of first excited pseudo-doublet in pyrazole-ligated complex $\mathbf{1 a} / \mathbf{3 a}$ is much larger than that in complex 1/3 (carbene ligated) reiterating our earlier statement of better SIM behaviour for carbene analogues. Hence, despite the lower energy magnitude of first excited pseudo-doublet for $\mathbf{3}\left(9.01 \mathrm{~cm}^{-1}\right)$ in comparison with 3a $\left(13.08 \mathrm{~cm}^{-1}\right)$, tunnel splitting dictates the magnetic behaviour and larger $\Delta_{\text {tun }}$ for 3a indicates poor SIM characteristics for $\mathbf{3 a}$. Thus, our calculations based on $\mathrm{U}_{\text {cal }}$ value predict the following trend: $\mathbf{1} \approx \mathbf{2}>\mathbf{1 a}>\mathbf{4}$ $>\mathbf{2 a}>\mathbf{3 a}>\mathbf{3}>\mathbf{4 a}$. The magnetic analysis of all the eight complexes are summarized in Table 2.

\subsection{Role of Ln-L Bonding in influencing Magnetic Anisotropy of complexes 1-4 and 1a-4a}

3.6a Charge and Spin Density Analysis: To understand the role of $\mathrm{CF}$ parameters and the $4 \mathrm{f}$-ligand interactions, we have analysed the charges and the spin 
Table 2. Comparative magnetic analysis on eight complexes studied.

\begin{tabular}{|c|c|c|c|c|}
\hline Complexes & $\begin{array}{c}\mathrm{U}_{\mathrm{eff}} \\
\left(\mathrm{cm}^{-1}\right)\end{array}$ & $\begin{array}{c}\mathrm{U}_{\mathrm{cal}} \\
\left(\mathrm{cm}^{-1}\right)\end{array}$ & $\begin{array}{l}\text { Experimental } \\
\text { relaxation } \\
\text { metrics }\end{array}$ & Calculated relaxation metrics \\
\hline 1 & $44.8(45.2)$ & 256.36 & - & $\begin{array}{l}\text { Via } 1^{\text {st }} \text { excited KD } \\
\Delta_{\text {tun }}=0.02 \text { and } 0.03 \mathrm{~cm}^{-1} \text { for ground and first } \\
\text { excited pseudo-doublet, respectively }\end{array}$ \\
\hline 2 & $32.8(33.6)$ & $268.50 *$ & $\mathrm{QTM}=3.1$ & $\begin{array}{l}\text { Via } 4^{\text {th }} \text { excited KD } \\
\text { QTM=0.03,0.03,0.03,0.05 and } 1.76 \mu_{\mathrm{B}} \text {, } \\
\text { respectively for ground, } 1^{\text {st }}, 2^{\text {nd }}, 3^{\text {rd }}, 4^{\text {th }}, 5^{\text {th }} \mathrm{KD}\end{array}$ \\
\hline 3 & - & 9.01 & - & $\begin{array}{l}\text { Via } 1^{\text {st }} \text { excited KD } \\
\Delta_{\text {tun }}=0.04 \text { and } 3.04 \mathrm{~cm}^{-1} \text { for ground and first } \\
\text { excited pseudo-doublet, respectively }\end{array}$ \\
\hline 4 & - & 23.29 & - & $\begin{array}{l}\text { Via } 1^{\text {st }} \text { excited } \mathrm{KD} \\
\mathrm{QTM}=3.16 \text { and } 0.05 \mu_{\mathrm{B}} \text {, respectively, for } \\
\text { ground and } 1^{\text {st }} \text { excited } \mathrm{KD}\end{array}$ \\
\hline $1 \mathbf{a}$ & 21 & 229.39 & $\mathrm{QTM}=115.9$ & $\begin{array}{l}\text { Via } 1^{\text {st }} \text { excited KD } \\
\Delta_{\text {tun }}=0.05 \text { and } 0.04 \mathrm{~cm}^{-1} \text { for ground and first } \\
\text { excited pseudo-doublet, respectively }\end{array}$ \\
\hline $2 \mathbf{a}$ & - & 23.19 & - & $\begin{array}{l}\text { Via } 1^{\text {st }} \text { excited KD } \\
\text { QTM }=0.02 \text { and } 0.10 \mu_{\mathrm{B}} \text {, respectively, for } \\
\text { ground and } 1^{\text {st }} \text { excited KD }\end{array}$ \\
\hline $3 \mathbf{a}$ & - & 13.08 & - & $\begin{array}{l}\text { Via } 1^{\text {st }} \text { excited KD } \\
\Delta_{\text {tun }}=0.07 \text { and } 12.35 \mathrm{~cm}^{-1} \text { for ground and } \\
\text { first excited pseudo-doublet, respectively }\end{array}$ \\
\hline $4 \mathbf{a}$ & - & 5.63 & - & $\begin{array}{l}\text { Via } 1^{\text {st }} \text { excited KD } \\
\text { QTM }=3.11 \text { and } 0.19 \mu_{\mathrm{B}} \text {, respectively, for } \\
\text { ground and } 1^{\text {st }} \text { excited KD }\end{array}$ \\
\hline
\end{tabular}

densities obtained from DFT calculations. In all the complexes, metal ions possess positive spin density while the six-coordinated $\mathrm{C}$ (for complexes $\mathbf{1}, \mathbf{2}, \mathbf{3}$, 4) and $\mathrm{N}$ (for complexes 1a, 2a, 3a, 4a) atoms show small negative spin density. This clearly reveals mixture of spin delocalization and polarization with preponderant spin polarization on the coordinated ligand donor atoms (Figure 5). Mulliken charge analysis predicts strong crystal field around the carbene ligated complexes as compared to their pyrazole analogues. This can be attributed to the negative charges on the $\mathrm{C}$ atoms of carbene ligands while positive charges were computed on the ligated nitrogen atoms of the pyrazole ligands (see Table 3 and for corresponding atomic numbers see Figure S2 in Supplementary Information). In order to gain insights into the orientation of principal anisotropy axis $\left(\mathrm{g}_{\mathrm{z}}\right)$, we have also performed analysis based on simple electrostatic model.$^{98}$ The calculated orientations of the magnetic moments of the ground state for $\mathbf{2}$ and $\mathbf{2 a}$ (Figure S1 in SI) resemble the alignment expected from $a b$ initio calculations (deviation between $a b$ initio and electrostatic anisotropic axis is $0.23^{\circ}$ and $0.48^{\circ}$ for $\mathbf{2}$ and $\mathbf{2 a}$, respectively).

3.6b NBO Analysis: To gain clues into the nature of Ln-L bonding, NBO calculations were also carried out on all the eight complexes to understand the $\mathrm{Ln}-\mathrm{H}-\mathrm{B}$ interactions. For all the complexes, we have focussed on the charge transfer interaction between B-H bond moiety and metal ion. On this note, we have computed charge transfer interaction stabilization energy from the donor $\sigma_{\mathrm{B}-\mathrm{H}}$ bond to the acceptor $\mathrm{p}-\mathrm{d}$ hybrid orbital of the $\mathrm{Ln}^{\mathrm{III}}$ ions. In all the complexes, NBO second order perturbation analysis reveals larger stabilization energy for the donor B-H bond to acceptor $\mathrm{Ln}^{\mathrm{III}}$ ions in the corresponding pyrazole ligated complexes as compared to their corresponding carbene analogues (see Figures S3-S18 in SI). This can be attributed to the larger bite angle, smaller $\mathrm{Ln}-\mathrm{H}$ distance of the pyrazole analogues. The Wiberg bond indexes computed for the Dy ${ }^{\mathrm{III}}-\mathrm{H}$ in $\mathbf{2}$ and $\mathbf{2 a}$ are 0.01 and 0.02 , respectively. This suggests the presence of stronger agostic interaction in pyrazole analogues compared to the carbene analogues (see section 3.6c). A similar trend was evident for all the carbene and pyrazole analogues of the three other metal ions $\left(\mathrm{Tb}^{\mathrm{III}}, \mathrm{Ho}^{\mathrm{III}}\right.$ and $\left.\mathrm{Er}^{\mathrm{III}}\right)$. The $\mathrm{NBO}$ analysis for $\mathbf{2}$ reiterates the nature of $\mathrm{B}-\mathrm{H}$ bonding between the two sites where $\mathrm{B}-\mathrm{H}$ is found to be strongly covalent possessing a significant $\sigma$ character with 45.91 Similarly, for $\mathbf{2 a}$ as well, 45.59 calculated for the B-H bond implying its $\sigma$-character. For all other six complexes, 45 corresponding B-H bonds. 


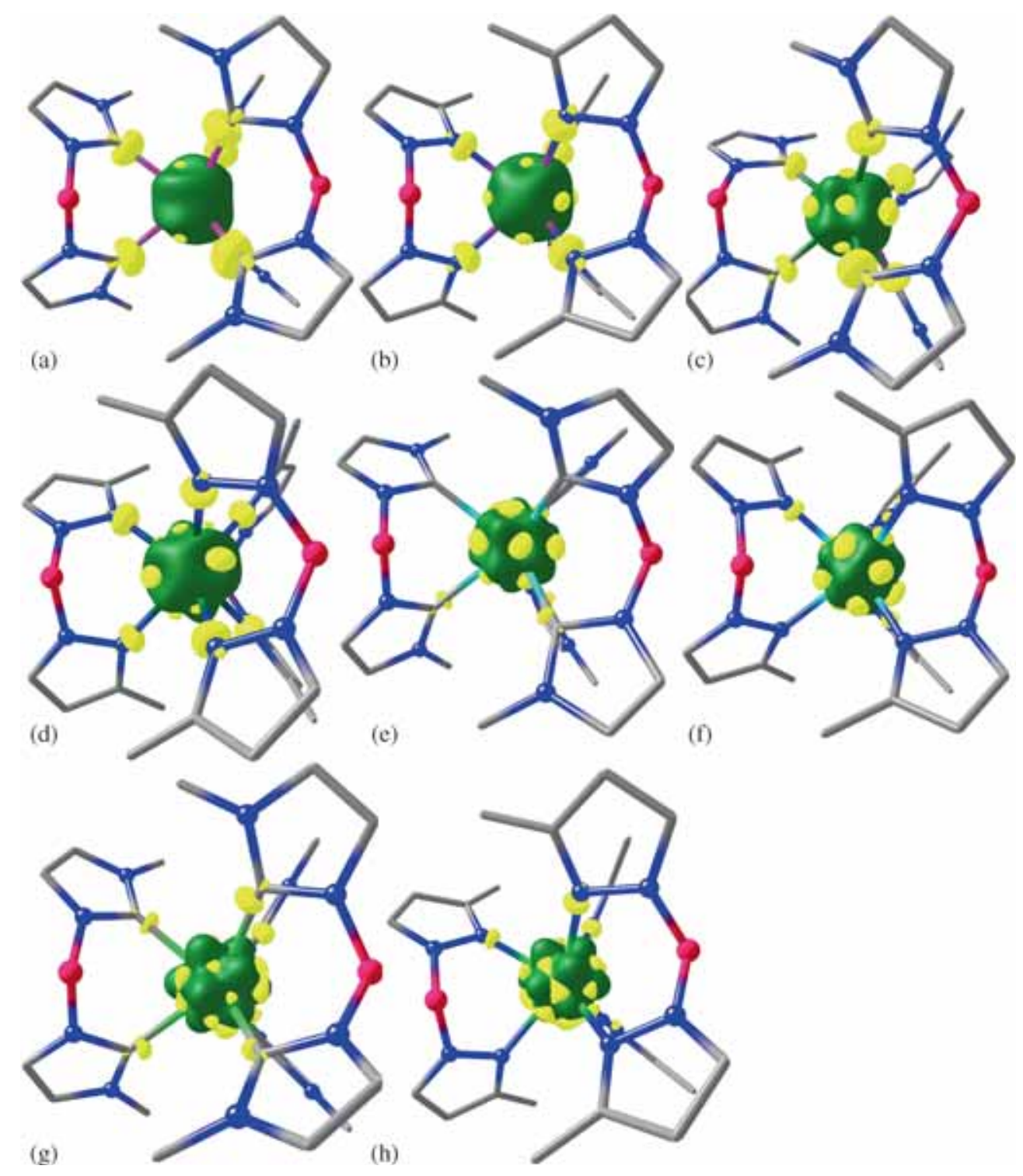

Figure 5. DFT-computed spin density plots for complexes; (a) 1, (b) 1a, (c) 2, (d) 2a, (e) $\mathbf{3}$, (f) $\mathbf{3 a},(\mathrm{g}) \mathbf{4}$ and (h) $\mathbf{4 a}$. The isodensity surface represented corresponds to a value of 0.0009 $\mathrm{e}^{-} / \mathrm{bohr}^{3}$. The green and yellow regions correspond to positive and negative spin densities, respectively.

3.6c QTAIM Analysis: We have investigated the topological properties at the bond critical point (BCPs) for the chosen complexes. All the systems analyzed here clearly display BCPs indicating the bonded and the non-bonded interactions that exist in the complexes. In the molecular graph (Figure S1 in SI), the big circles correspond to attractors attributed to positions of atoms and critical points such as $(3,-1) \mathrm{BCP}$ (red), $(3,+1)$ $\mathrm{RCP}$ (yellow) and $(3,+3) \mathrm{CCP}$ (green) indicated by small circles.

The topological properties at BCPs for $\mathrm{Ln}-\mathrm{C}(\mathrm{N})$ and $\mathrm{Ln} \cdots \mathrm{H}-\mathrm{BH}$ is collected in Tables 4 and 5 (complete topological properties are given in Tables S10 and S11 in Supporting Information) respectively. The lanthanide
(Ln) atom forms six bonds with each $\mathrm{C} / \mathrm{N}$ atom of the three ligand (via $\mathrm{C}$ or $\mathrm{N}$ ). It is seen that in all the complexes, there are mainly two different bond paths have been observed between Ln and ligand. Among them, six interactions are $\mathrm{Ln} \cdots \mathrm{C}(\mathrm{N})$ type and remaining three are $\mathrm{Ln} \cdots \mathrm{H}-\mathrm{BH}$ type agostic interactions (refer Figure S19 in SI). In addition to this several other interactions also present.

The electron density $\rho(r)$ at the BCP between $\mathrm{Ln}$ and the $\mathrm{C} 1 / \mathrm{N} 1$ atoms of $\mathbf{1 - 4}$ and $\mathbf{1 a - 4 a}$ shows values of $0.0467,0.0458,0.0478,0.0351$ and $0.0458,0.0477$, 0.0454 and $0.0623 \mathrm{au}$, respectively. It is seen that $\rho(r)$ is small $(0.0363 \mathrm{au}<\rho(r)<0.0986 \mathrm{au})$ and $\nabla_{\rho_{(r)}}^{2}$ is small positive $\left(0.0277 \mathrm{au}<\nabla_{\rho_{(r)}}^{2}<0.16642 \mathrm{au}\right)$, indicating 
Table 3. DFT-computed Mulliken charges for complexes 1-4 and 1a-4a, where the atomic number of respective complexes have been taken from pictorial representation (Figure S2 in Supplementary Information) of the core structure containing metals with six-coordination number ligated donor atoms.

\begin{tabular}{|c|c|c|c|c|c|c|c|}
\hline Complex 1 & Mulliken charge & Complex 1a & Mulliken charge & Complex 2 & Mulliken charge & Complex $\mathbf{2 a}$ & Mulliken charge \\
\hline $\mathrm{Tb}^{\mathrm{III}}$ & 0.84 & $\mathrm{~Tb}^{\mathrm{III}}$ & 1.59 & Dy ${ }^{I I I}$ & 0.86 & Dy ${ }^{\text {III }}$ & 1.62 \\
\hline $\mathrm{C} 1$ & -0.19 & N1 & 0.07 & $\mathrm{C} 1$ & -0.19 & N1 & 0.06 \\
\hline $\mathrm{C} 2$ & -0.23 & $\mathrm{~N} 2$ & 0.06 & $\mathrm{C} 2$ & -0.24 & $\mathrm{~N} 2$ & 0.07 \\
\hline $\mathrm{C} 3$ & -0.19 & N3 & 0.07 & C3 & -0.19 & N3 & 0.06 \\
\hline $\mathrm{C} 4$ & -0.24 & N4 & 0.07 & $\mathrm{C} 4$ & -0.24 & N4 & 0.07 \\
\hline C5 & -0.19 & N5 & 0.06 & $\mathrm{C} 5$ & -0.19 & N5 & 0.06 \\
\hline C6 & -0.24 & N6 & 0.06 & C6 & -0.24 & N6 & 0.07 \\
\hline Complex $\mathbf{3}$ & Mulliken charge & Complex 3a & Mulliken charge & Complex 4 & Mulliken charge & Complex $\mathbf{4 a}$ & Mulliken charge \\
\hline $\mathrm{Ho}^{\mathrm{III}}$ & 0.55 & $\mathrm{Ho}^{\mathrm{III}}$ & 1.43 & $\mathrm{C} 1$ & -0.19 & N1 & 0.05 \\
\hline $\mathrm{C} 1$ & -0.20 & N1 & 0.10 & $\mathrm{C} 2$ & -0.23 & $\mathrm{~N} 2$ & 0.08 \\
\hline $\mathrm{C} 2$ & -0.14 & $\mathrm{~N} 2$ & 0.08 & $\mathrm{Er}^{\mathrm{III}}$ & 0.80 & $\mathrm{Er}^{\mathrm{III}}$ & 1.55 \\
\hline C3 & -0.20 & N3 & 0.10 & $\mathrm{C} 4$ & -0.24 & N3 & 0.05 \\
\hline C4 & -0.14 & N4 & 0.09 & C5 & -0.18 & N4 & 0.08 \\
\hline C5 & -0.20 & N5 & 0.10 & C6 & -0.24 & N5 & 0.05 \\
\hline C6 & -0.14 & N6 & 0.08 & C3 & -0.18 & N6 & 0.08 \\
\hline
\end{tabular}

Table 4. Topological parameters at BCPs in the $\mathrm{Ln}-\mathrm{C}(\mathrm{N})$ bonds of the complexes $\mathbf{1}-\mathbf{4}$ and $\mathbf{1 a}-\mathbf{4 a} . \rho(r)$ in units of e $\AA^{-3}$.

\begin{tabular}{|c|c|c|c|c|c|c|c|c|c|c|c|c|}
\hline \multirow[b]{2}{*}{ Complexes } & \multicolumn{2}{|c|}{$\begin{array}{c}\mathrm{Ln}-\mathrm{C} 1(\mathrm{~N} 1) \\
\text { bonds }\end{array}$} & \multicolumn{2}{|c|}{$\begin{array}{c}\mathrm{Ln}-\mathrm{C} 2(\mathrm{~N} 2) \\
\text { bonds }\end{array}$} & \multicolumn{2}{|c|}{$\begin{array}{c}\mathrm{Ln}-\mathrm{C} 3(\mathrm{~N} 3) \\
\text { bonds }\end{array}$} & \multicolumn{2}{|c|}{$\begin{array}{c}\mathrm{Ln}-\mathrm{C} 4(\mathrm{~N} 4) \\
\text { bonds }\end{array}$} & \multicolumn{2}{|c|}{$\begin{array}{c}\mathrm{Ln}-\mathrm{C} 5(\mathrm{~N} 5) \\
\text { bonds }\end{array}$} & \multicolumn{2}{|c|}{$\begin{array}{c}\mathrm{Ln}-\mathrm{C} 6(\mathrm{~N} 6) \\
\text { bonds }\end{array}$} \\
\hline & $\rho(r)$ & $\nabla_{\rho_{(r)}}^{2}$ & $\rho(r)$ & $\nabla_{\rho_{(r)}}^{2}$ & $\rho(r)$ & $\nabla_{\rho_{(r)}}^{2}$ & $\rho(r)$ & $\nabla_{\rho_{(r)}}^{2}$ & $\rho(r)$ & $\nabla_{\rho_{(r)}}^{2}$ & $\rho(r)$ & $\nabla_{\rho_{(r)}}^{2}$ \\
\hline 1 & & 7 & & & & & & & & & & \\
\hline 2 & 0.0458 & 0.0259 & 0.0470 & 0.0265 & 0.0459 & 0.0263 & 0.0471 & 0.0266 & 0.0455 & 0.0277 & 56 & 0.0278 \\
\hline 3 & 0.0478 & 0.0296 & 0.0467 & 0.0291 & 0.0479 & 0.0310 & 0.0466 & 0.0293 & 0.0478 & 0.0299 & 0.0465 & 0.0289 \\
\hline 4 & 0.0351 & 0.0730 & 0.0853 & 0.1030 & 0.0368 & 0.0750 & 0.0859 & 0.1099 & 0.0299 & 0.0527 & 0.0816 & 0.1001 \\
\hline $1 \mathrm{a}$ & 0.0458 & 0.0382 & 0.0467 & 0.0394 & 0.0458 & 0.0382 & 0.0467 & 0.0393 & 0.0456 & 0.0384 & 0.0466 & 0.0400 \\
\hline $2 \mathbf{a}$ & 0.0477 & 0.0375 & 0.0466 & 0.0373 & 0.0477 & 0.0381 & 0.0469 & 0.0372 & 0.0476 & 0.0373 & 0.0465 & 0.0367 \\
\hline $3 \mathbf{a}$ & 0.0454 & 0.0398 & 0.0467 & 0.0415 & 0.0459 & 0.0398 & 0.0470 & 0.0412 & 0.0451 & 0.0397 & 0.0467 & 0.0407 \\
\hline $4 a$ & 0.0623 & 0.1007 & 0.0986 & 0.1641 & 0.0906 & 0.1463 & 0.0920 & 0.1642 & 0.1010 & 0.1629 & 0.0962 & 0.1664 \\
\hline
\end{tabular}

Table 5. Topological parameters at BCPs in the $\mathrm{Ln} \cdots \mathrm{H}-\mathrm{BH}$ bonds of the complexes 1-4 and 1a-4a. $\rho(r)$ in units of $\mathrm{e}^{-3}$.

\begin{tabular}{|c|c|c|c|c|c|c|}
\hline \multirow[b]{2}{*}{ Complexes } & \multicolumn{2}{|c|}{ Ln $\cdots \mathbf{H 1 - B H}$} & \multicolumn{2}{|c|}{ Ln $\cdots \mathbf{H} 2-\mathbf{B H}$} & \multicolumn{2}{|c|}{ Ln $\cdots \mathbf{H}-\mathbf{B H}$} \\
\hline & $\rho(r)$ & $\nabla_{\rho_{(r)}}^{2}$ & $\rho(r)$ & $\nabla_{\rho_{(r)}}^{2}$ & $\rho(r)$ & $\nabla_{\rho_{(r)}}^{2}$ \\
\hline 1 & 0.0112 & 0.0115 & 0.0112 & 0.0113 & 0.0112 & 0.0115 \\
\hline 2 & 0.0106 & 0.0105 & 0.0107 & 0.1056 & 0.0106 & 0.0105 \\
\hline 3 & 0.0114 & 0.0120 & 0.0114 & 0.0121 & 0.0114 & 0.0118 \\
\hline 4 & 0.0031 & 0.0043 & 0.0323 & 0.0040 & 0.0334 & 0.0154 \\
\hline $1 \mathbf{a}$ & 0.0209 & 0.0184 & 0.0208 & 0.0180 & 0.0208 & 0.0183 \\
\hline $2 \mathbf{a}$ & 0.0192 & 0.0158 & 0.0193 & 0.0158 & 0.0193 & 0.0158 \\
\hline $3 \mathbf{a}$ & 0.0198 & 0.0191 & 0.0202 & 0.0187 & 0.0199 & 0.0192 \\
\hline $4 \mathbf{a}$ & 0.0563 & 0.0552 & 0.0543 & 0.0630 & 0.0529 & 0.0638 \\
\hline
\end{tabular}

a "closed" shell character of the coordination bonds. 99 The electron density $\rho(r)$ at the BCP between Ln and other carbon atoms (C2, C3, C4, C5 and C6) follows the same trend. The partly covalent nature of investigated interactions can then be supported by values of
$|\mathrm{V}(\mathrm{r})| / \mathrm{G}(\mathrm{r})$ ratio. $^{99,100}|\mathrm{~V}(\mathrm{r})| / \mathrm{G}(\mathrm{r})<1$ is characteristic of a typical ionic interaction and $|\mathrm{V}(\mathrm{r})| \mathrm{G}(\mathrm{r})>2$ is diagnostic of a 'classical' covalent interaction. Taking all these criteria into consideration, the QTAIM-defined topological properties at BCPs indicate a mixed (largely 
ionic with significant covalent component) character of these coordination bonds, also because $\mid \mathrm{V}(\mathrm{r}) / / \mathrm{G}(\mathrm{r})$ $<\sim 1.16$ condition has been met in all cases. The Laplacian function $\nabla_{\rho_{(r)}}^{2}$ at the BCP between Ln and the $\mathrm{C} 1 / \mathrm{N} 1$ atoms of $\mathbf{1 - 4}$ and $\mathbf{1 a - 4 a}$ shows values of 0.00277, 0.0259, 0.0296, 0.0730 and 0.0382, 0.0375, 0.0398 and 0.1007 au for Tb, Dy, Ho and Er, respectively. All other Ln-C and Ln-N bonds also shows similar values Laplacian function $\nabla_{\rho_{(r)}}^{2}$. Based on QTAIM analysis, it is interesting to note that the pyrazole ligated $\mathrm{Ln}-\mathrm{C}$ bonds $(\mathbf{1 a}-\mathbf{4 a})$ are stronger as compared to carbine ligated complexes (1-4).

Figure 6 shows comparative plots of the negative Laplacian function $\nabla_{\rho_{(r)}}^{2}$ through $\mathrm{Ln}-\mathrm{C}$ and $\mathrm{Ln}-\mathrm{N}$ plane for complex $\mathbf{2}$ and $\mathbf{2 a}$. It is evident that the valence shell charge concentration (VSCC) zone of the carbenic carbon atom is more diffused towards the group Dy atom in complex 2 (Figure 6) than in complex 2a. This indicates that there is a larger charge transfer from the carbenic $\mathrm{C}$ atom to the Dy atom than $\mathrm{N}$ atom. The calculated topological properties at the $\mathrm{BCP}$ between the interacting atoms with the corresponding ligand suggest that as the size of the atom increases, the charge density at $\mathrm{BCP}$ decreases.

To ascertain the nature of the interaction between the $\mathrm{H}-\mathrm{BH}$ and Ln, AIM analysis was performed. In all the cases, the $\rho(r)$ values are 0.0112 to $0.0209 \mathrm{au}$ which indicates a weak interaction as expected. In addition, all the interactions investigated in the $\mathrm{Ln} \cdots \mathrm{H}$ BCPs are characterized by positive values of $\rho(r)$ and $\nabla_{\rho_{(r)}}^{2}$ which suggest that it should be considered as closedshell interactions of agostic type. The $\mathrm{IV}(r) \mid \mathrm{G}(r)<1.0$ is also met, indicating partly covalent $\mathrm{Ln} \cdots \mathrm{BH}$ interactions for all the complexes. The QTAIM results show that the agostic bonds are characterized by $\mathrm{Ln} \cdots \mathrm{H}-$ $\mathrm{BH}$ bond paths that are straight in the $\mathrm{Ln}$ - BCP section and highly curved near the agostic hydrogen (refer Figure S19 in SI). The ellipticity $(\varepsilon)$ computed at $\mathrm{Ln} \cdots \mathrm{H}-\mathrm{BH} \mathrm{BCP}$ has greater values, which also confirms the presence of agostic interaction. This agrees well with the earlier reports. ${ }^{101-104}$ It is important to note that $\mathrm{BCP}$ is significantly closer to the agostic hydrogen in complexes with $\mathrm{Ln} \cdots \mathrm{H}-\mathrm{BH}$ agostic bonds (Figure 7).
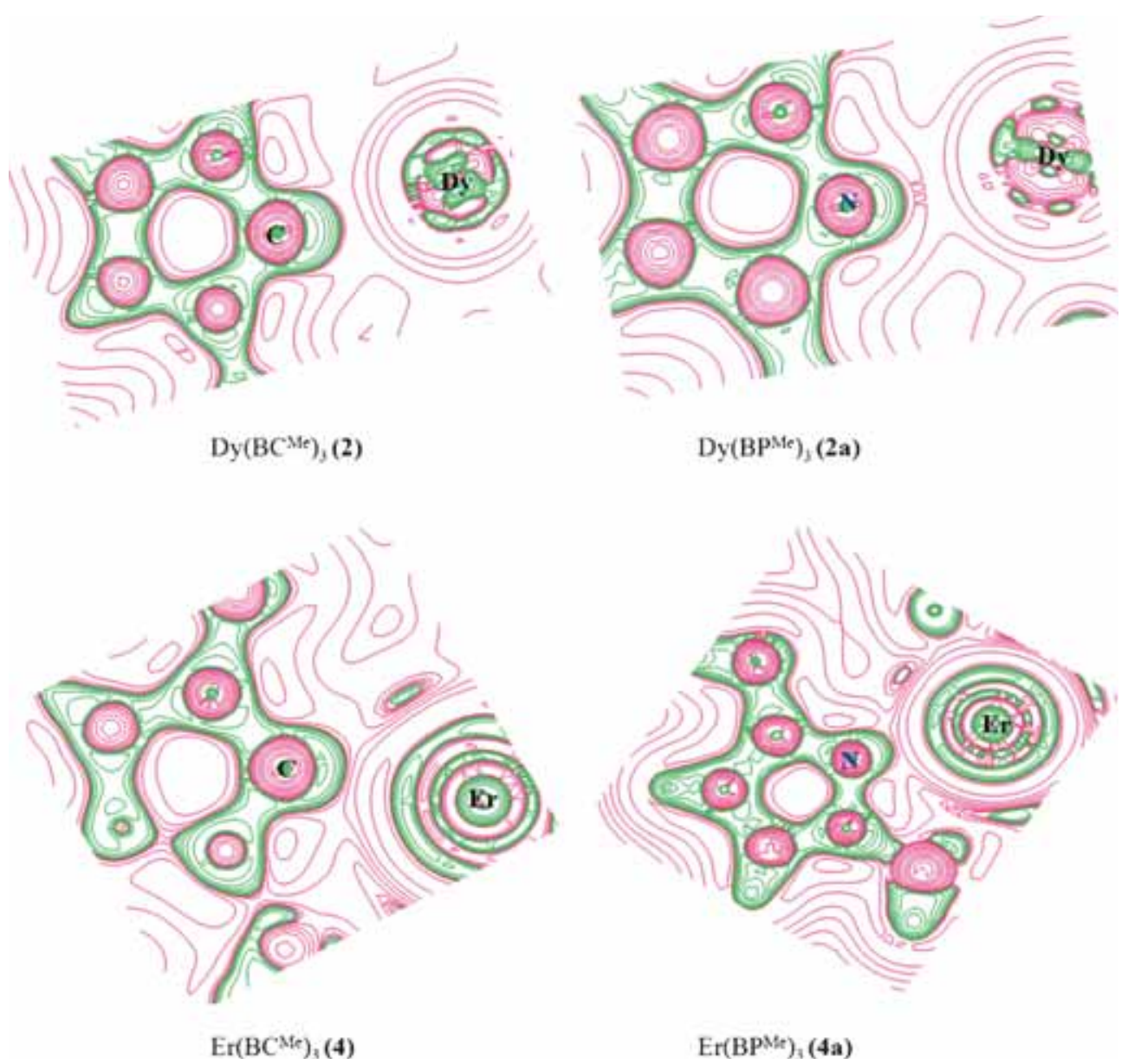

Figure 6. Contour line diagram of the Laplacian of electron density along the Ln-C/Ln-N plane in complexes $\mathbf{2}, \mathbf{2} \mathbf{a}$ and $\mathbf{4}, \mathbf{4 a}$. 


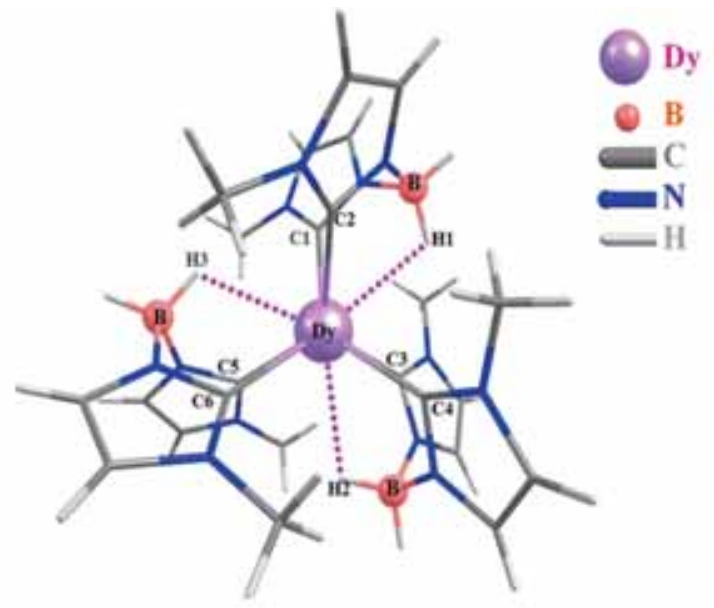

Crystal Structure

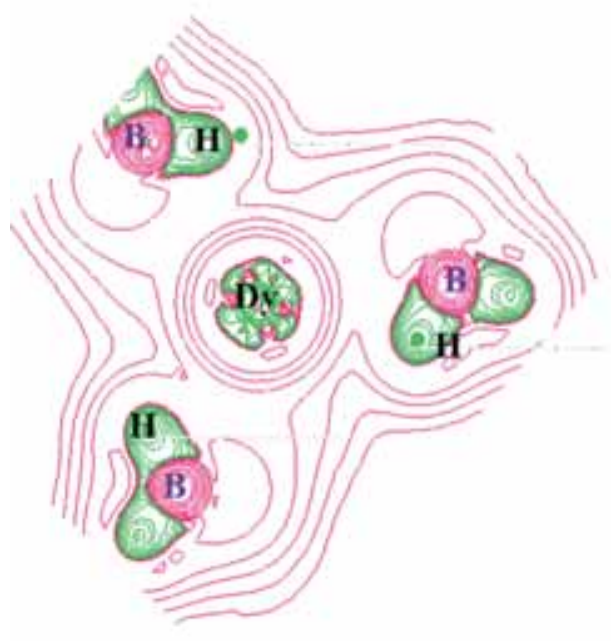

$\operatorname{Dy}\left(\mathrm{BC}^{\mathrm{Me}}\right)_{3}(2)$

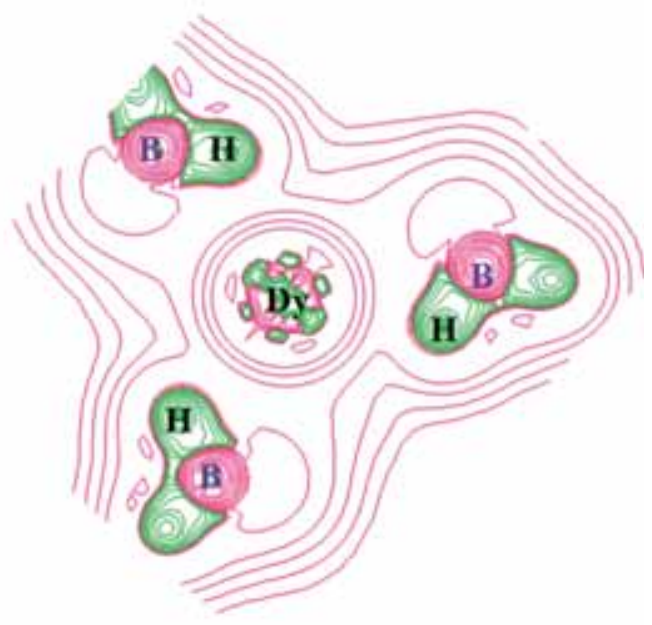

$\operatorname{Dy}\left(\mathrm{BPMe}_{3}(\mathbf{2 a})\right.$

Figure 7. Top - Crystal structure showing agostic interactions. Bottom - Contour line diagram of the Laplacian of electron density along the three agostic Ln $\cdots \mathrm{H}-\mathrm{BH}$ interactions (drawn on the agostic plane) in $\mathrm{Dy}\left(\mathrm{BC}^{\mathrm{Me}}\right)_{3}(\mathbf{2})$ and $\mathrm{Dy}\left(\mathrm{BC}^{\mathrm{Me}}\right)_{3}(\mathbf{2 a})$.

In all the complexes, the three $\mathrm{Ln} \cdots \mathrm{H}-\mathrm{BH}$ interactions make the tricapped trigonal prismatic geometry around the metal centre. The Lanthanide atoms make bonds with the three ligands via six carbon (C1-C2, C3$\mathrm{C} 4$ and $\mathrm{C} 5-\mathrm{C} 6)$ and six nitrogen atoms (N1-N2, N2-N4 and N5-N6) for 1-4 and 1a-4a, respectively. Among them $\mathrm{C} 1, \mathrm{C} 3, \mathrm{C} 5(\mathrm{~N} 1, \mathrm{~N} 3, \mathrm{~N} 5)$ and $\mathrm{C} 2, \mathrm{C} 4, \mathrm{C} 6(\mathrm{~N} 2$, $\mathrm{N} 4, \mathrm{~N} 6)$ make triangles. The ab initio results show that, the main anisotropic g-tensor is oriented perpendicular to the $\mathrm{Ln} \cdots \mathrm{H}-\mathrm{BH}$ interactions and centre of the $\mathrm{C} 1$, $\mathrm{C} 3, \mathrm{C} 5(\mathrm{~N} 1, \mathrm{~N} 3, \mathrm{~N} 5)$ triangle. This is due to the presence of three $\mathrm{Ln}$ ' $\mathrm{H}-\mathrm{BH}$ interactions and the $\mathrm{C} 1, \mathrm{C} 3, \mathrm{C} 5$ (N1, N3, N5) triangle. The Laplacian of electron density drawn along the three carbon (C-C-C) plane in $\mathbf{2}$ and $\mathbf{2 a}$ shows less charge concentration in the triange 1 (Figure S20 in SI).
To probe and quantify the prolate and oblate nature of the electron density the comparative plots of the negative Laplacian function $\nabla_{\rho_{(r)}}^{2}$ through Ln-C and Ln-N plane has been analysed. The Laplacian function $\nabla_{\rho_{(r)}}^{2}$ value against this general prolate-oblate classification is plotted in Figure 8. Quite interestingly, the Laplacian function $\nabla_{\rho_{(r)}}^{2}$ was found to quantify the qualitative oblate-prolate nature of the electron density with values larger than 0.07 au describing prolate shape and smaller values classified as oblate. Within the oblate set studied, the $\mathrm{Tb}$ is found to possess stronger oblate character followed by Dy and Ho. This is strikingly matching with the expectation based on the popular qualitative analysis ${ }^{50}$ except for the fact that Laplacian function $\nabla_{\rho_{(r)}}^{2}$ explicitly quantify them based on the ligand field employed. The same is also visible 


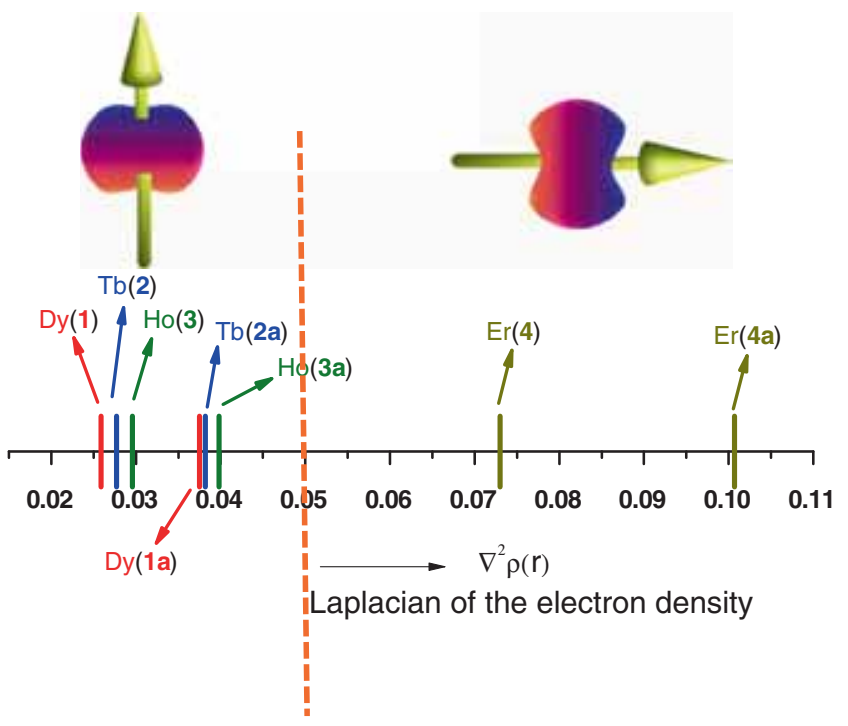

Figure 8. The Laplacian function $\nabla_{\rho_{(r)}}^{2}$ value plotted against general prolate-oblate classification.

when the Laplacian function $\nabla_{\rho_{(r)}}^{2}$ is plotted at the Ln-L plane.

\section{Conclusions}

To summarise, we have undertaken a detailed ab initio and DFT, QTAIM calculations on a series of lanthanide $\mathrm{M}\left(\mathrm{Bc}^{\mathrm{Me}}\right)_{3}\left(\mathrm{M}=\mathrm{Tb}(\mathbf{1}), \operatorname{Dy}(\mathbf{2}), \operatorname{Ho}(\mathbf{3}), \operatorname{Er}(\mathbf{4}),\left[\mathrm{Bc}^{\mathrm{Me}}\right]^{-}=\right.$ dihydrobis(methylimidazolyl)borate) and $\mathrm{M}\left(\mathrm{Bp}^{\mathrm{Me}}\right)_{3}$ $\left(\mathrm{M}=\mathrm{Tb}(\mathbf{1 a}), \operatorname{Dy}(\mathbf{2 a}), \operatorname{Ho}(\mathbf{3 a}), \operatorname{Er}(\mathbf{4 a})\left[\mathrm{Bp}^{\mathrm{Me}}\right]^{-}=\right.$dihydrobis(methypyrazolyl)borate) complexes to shed light on the magnetic properties and to probe how lanthanideligand bonding influences the magnetic properties. Conclusions drawn from our work are summarized below:

1. Our calculations reproduced experimental absence/ presence of SIM characteristic for all the eight studied complexes nicely (except complex 1a). Among all the eight complexes studied, only complexes 1 and 2 show SIM behaviour with $\mathrm{U}_{\text {cal }} / \mathrm{U}_{\text {eff }}$ values of $256.4 / 45.2$ and $268.5 / 33.6 \mathrm{~cm}^{-1}$ for $\mathbf{1}$ and 2 , respectively.

2. Experimentally, though complex 1a only shows variable field frequency dependent $\chi$ " tails $\left(\mathrm{U}_{\text {eff }}=\right.$ $21 \mathrm{~cm}^{-1}$ ), our calculations reveal much larger energy barrier of $229.4 \mathrm{~cm}^{-1}$ contrary to experiment. Small computed barrier height for complex 2a $\left(23.2 \mathrm{~cm}^{-1}\right)$ justifies the experimentally observed frequency dependent $\chi$ " tails Rest of the four complexes $(\mathbf{3}, \mathbf{4}, \mathbf{3} \mathbf{a}$ and $\mathbf{4 a})$ lack SIM characteristics. Hence, in this set of complexes, $\mathrm{Tb}^{\mathrm{III}}\left(4 \mathrm{f}^{8}\right)$ and Dy ${ }^{\text {III }}\left(4 \mathrm{f}^{9}\right)$ ions are found to instil improved SIM behaviour as compared to $\mathrm{Ho}^{\mathrm{III}}\left(4 \mathrm{f}^{10}\right) / \mathrm{Er}^{\mathrm{III}}\left(4 \mathrm{f}^{11}\right)$ ions.

3. Correlation between ligand field environment and nature of $4 \mathrm{f}$ electron density has been corroborated by our calculations. Axial positioning of the ligand ( $\mathrm{N}$-heterocyclic carbene or bis(pyrazolyl) borate) has favoured stabilisation of energy multiplet with larger angular momentum projection; i.e., $\pm \mathrm{m}_{\mathrm{J}}=15 / 2$, $\mathbf{2} \mathbf{a}$ and $\mathbf{3 a}$ for $\mathrm{Dy}^{\mathrm{III}}, \mathrm{Tb}^{\mathrm{III}}$ and $\mathrm{Ho}^{\mathrm{III}}$ ions with $4 \mathrm{f}$ oblate electron density respectively. However, in $\mathrm{Er}^{\mathrm{III}}$ compounds (prolate $4 \mathrm{f}$ electron density), lowest angular momentum multiplet was computed to be the ground state $\left( \pm \mathrm{m}_{\mathrm{J}}=1 / 2\right)$ as such metal ions necessitate presence of equatorial crystal field.

4. Calculations yield the following trend in the $U_{\text {cal }}$ values: $1 \approx \mathbf{2}>\mathbf{1 a}>\mathbf{4}>\mathbf{2 a}>\mathbf{3 a}>\mathbf{3}>\mathbf{4 a}$ and this is consistent with the experimental observations. We have also attempted to ascertain the location of anisotropy orientation which pierces out amidst the six coordinated ligand donor atoms of the three coordinating ligands in order to minimise electrostatic repulsion.

5. DFT-computed Mulliken charge analysis clearly revealed larger negative charges on the coordinated $\mathrm{C}$-atoms of carbene ligand while small positive charge was detected on coordinated $\mathrm{N}$-atoms of the pyrazole ligand. This essentially leads to stronger crystal field environment for carbene analogues. NBO and Wiberg bond index analysis also reaffirmed the presence of stronger $\mathrm{Ln} \cdots \mathrm{H}-\mathrm{B}$ agostic interaction for the pyrazole analogues as compared to their carbene analogues.

6. QTAIM analysis provides evidence for a direct interaction between the agostic hydrogen atom and the metal, viz., smaller $\rho(r)$ values at the $\mathrm{Ln} \cdots \mathrm{H}-\mathrm{BH}$, larger $\varepsilon$ of the $\mathrm{Ln} \cdots \mathrm{H}-\mathrm{BH}$ BCPs. Most importantly, the Laplacian function $\nabla_{\rho_{(r)}}^{2}$ was found to quantify the qualitative oblate-prolate nature of the electron density explicitly based on the ligand field employed and this is likely to have influence beyond the example presented.

\section{Supplementary Information (SI)}

We have summarised the energies $\left(\mathrm{cm}^{-1}\right)$, corresponding g-tensors, tunnel splitting $\left(\mathrm{cm}^{-1}\right)$, crystal field parameters and angle between main magnetic axis of ground state energy multiplet and higher excited levels of all the Kramers doublets and pseudo-doublets in $\mathbf{2}$, 2a, 4, 4a and 1, 1a, 3, 3a, respectively, in Tables S1-S9. The orientation of the principal anisotropy axis (gz) for complexes a) $\mathbf{2}$ and b) $\mathbf{2 a}$ are given in Figure S1. The 
core structural moieties of complexes atom numbers correspond to the representation of Mulliken charges are given in the Figure S2. The second-order perturbation theory computed donor-acceptor charge transfer stabilisation energy in all the eight complexes are given in Figures S3-S18. The molecular graphs of the complexes and the contour line diagram of the Laplacian of electron density drawn along the three carbon (C-C-C) plane are given in the Figures S19 and S20 respectively.

\section{Acknowledgements}

GR would like to thank SERB (EMR/2014/00024) for the funding. TG would like to thank UGC New Delhi for SRF fellowship. GV would like to thank Indian Institute of Technology Bombay for Post-Doctoral fellowship.

\section{References}

1. Wang H, Wang B-W, Bian Y, Gao S and Jiang J 2016 Coord. Chem. Rev. 306195

2. Liddle S T and van Slageren J 2015 Chem. Soc. Rev. 44 6655

3. Feltham H L C and Brooker S 2014 Coord. Chem. Rev. 2761

4. Woodruff D N, Winpenny R E P and Layfield R A 2013 Chem. Rev. 1135110

5. Wang B W, Wang X Y, Sun H L, Jiang S D and Gao S 2013 Philos. Trans. R. Soc. London, Ser. A 371 20120316

6. Habib F and Murugesu M 2013 Chem. Soc. Rev. 42 3278

7. Sorace L, Benelli C and Gatteschi D 2011 Chem. Soc. Rev. 403092

8. Friedman J R and Sarachik M P 2010 Аnnu. Rev. Condens. Matter Phys. 1109

9. Luzon J and Sessoli R 2012 Dalton Trans. 4113556

10. Wang B, Jiang S, Wang X and Gao S 2009 Sci. China, Ser. B Chem. $\mathbf{5 2} 1739$

11. Sessoli R and Powell A K 2009 Coord. Chem. Rev. 253 2328

12. Ishikawa N 2007 Polyhedron 262147

13. Pedersen K S, Bendix J and Clerac R 2014 Chem. Commun. $\mathbf{5 0} 4396$

14. Saitoh E, Miyajima H, Yamaoka T and Tatara G 2004 Nature $\mathbf{4 3 2} 203$

15. Leuenberger M N and Loss D 2001 Nature $\mathbf{4 1 0} 789$

16. Yamanouchi M, Chiba D, Matsukura $\mathrm{F}$ and Ohno $\mathrm{H}$ 2004 Nature 428539

17. Bogani L and Wernsdorfer W 2008 Nat. Mater. 7179

18. Xiong G, Qin X Y, Shi P F, Hou Y L, Cui J Z and Zhao B 2014 Chem. Commun. 504255

19. Li D P, Wang T W, Li C H, Liu D S, Li Y Z and You X Z 2010 Chem. Commun. 462929

20. Baldoví J J, Cardona-Serra S, Clemente-Juan J M, Coronado E, Gaita-Ariño A and Palii A 2012 Inorg. Chem. 5112565
21. Meihaus K R and Long J R 2013 J. Am. Chem. Soc. 13517952

22. Chen G J, Guo Y N, Tian J L, Tang J, Gu W, Liu X, Yan S P, Cheng P and Liao D Z 2012 Chem. Eur. J. 18 2484

23. Ungur L, Le Roy J J, Korobkov I, Murugesu M and Chibotaru L F 2014 Angew. Chem. Int. Ed. 534413

24. Clemente-Juan J M, Coronado E and Gaita-Ariño A 2015 In Lanthanides and Actinides in Molecular Magnetism (Weinheim: Wiley-VCH Verlag) pp. 27-60

25. Jiang S-D, Wang B-W and Gao S 2014 (Berlin Heidelberg: Springer) pp. 1-31

26. Ganivet C R, Ballesteros B, de la Torre G, ClementeJuan J M, Coronado E and Torres T 2013 Chem. Eur. J. 191457

27. Sun W-B, Yan P-F, Jiang S-D, Wang B-W and Zhang Y-Q 2016 Chem. Sci. 7684

28. Jeletic M, Lin P H, Le Roy J J, Korobkov I, Gorelsky S I and Murugesu M $2011 \mathrm{~J}$. Am. Chem. Soc. 13319286

29. Ishikawa N, Sugita M, Ishikawa T, Koshihara $S$ and Kaizu Y 2003 J. Am. Chem. Soc. 1258694

30. Aromi G and Brechin E K 2006 Struct. Bond. 1221

31. Ishikawa N, Sugita M, Ishikawa T, Koshihara S and Kaizu Y 2004 J. Phys. Chem. B 10811265

32. Gregson M, Chilton N F, Ariciu A-M, Tuna F and Crowe I F 2016 Chem. Sci. 7155

33. Chilton N F, Langley S K, Moubaraki B, Soncini A, Batten S R and Murray K S 2013 Chem. Sci. 41719

34. Boulon M E, Cucinotta G, Luzon J, Degl'Innocenti C and Perfetti M 2013 Angew. Chem. Int. Ed. 52350

35. Chilton N F 2015 Inorg. Chem. 542097

36. Chilton N F, Goodwin C A P, Mills D P and Winpenny R E P 2015 Chem. Commun. 51101

37. Blackburn O A, Chilton N F, Keller K, Tait C E and Myers W K 2015 Angew. Chem. Int. Ed. 5410783

38. Mei X-L, Ma Y, Li L-C and Liao D-Z 2012 Dalton Trans. $\mathbf{4 1} 505$

39. Gatteschi D and Sorace L 2001 J. Solid State Chem. 159253

40. Rechkemmer Y, Fischer J E, Marx R, Dörfel M and Neugebauer P 2015 J. Am. Chem. Soc. 13713114

41. Chen Y-C, Liu J-L, Ungur L, Liu J and Li Q-W 2016 J. Am. Chem. Soc. 1382829

42. Goswami T and Misra A 2012 J. Phys. Chem. A 1165207

43. Pedersen K S, Ungur L, Sigrist M, Sundt A and Schau-Magnussen M 2014 Chem. Sci. 51650

44. Oyarzabal I, Ruiz J, Ruiz E, Aravena D and J M Seco 2015 and, Colacio E Chem. Commun. 5112353

45. Chen G-J, Gao C-Y, Tian J-L, Tang J and Gu W 2011 Dalton Trans. 405579

46. Mondal A K, Goswami S and Konar S 2015 Dalton Trans. 445086

47. Wang Y-L, Gu B, Ma Y, Xing C and Wang Q-L 2014 CrystEngComm 162283

48. Pugh T, Tuna F, Ungur L, Collison D and McInnes E J L 2015 Nat. Commun. 67492

49. Das S, Bejoymohandas K S, Dey A, Biswas S, Reddy M L P and et al. 2015 Chem. Eur. J. 216449

50. Rinehart J D and Long J R 2011 Chem. Sci. 22078

51. Gudel H U, Hauser U and Furrer A 1979 Inorg. Chem 182730 
52. Amoretti G, Caciuffo R, Carretta S, Guidi T, Magnani $\mathrm{N}$ and Santini P 2008 Inorg. Chim. Acta 3613771

53. Bencini A and Gatteschi D 1990 In EPR of Exchange Coupled Systems (Berlin: Springer-Verlag)

54. Barra A L, Gatteschi D, Sessoli R, Abbati G L and Cornia A 1997 Angew. Chem. Int. Ed. 362329

55. Liu J, Chen Y-C, Jia J-H, Liu J-L and Vieru V 2016 J. Am. Chem. Soc. 1385441

56. Ungur L and Chibotaru L F 2015 In Lanthanides and Actinides in Molecular Magnetism (Weinheim: WileyVCH Verlag) pp. 153-184

57. Huang X-C, Vieru V, Chibotaru L F, Wernsdorfer W, Jiang S-D and Wang X-Y 2015 Chem. Commun. 51 10373

58. Marx R, Moro F, Dorfel M, Ungur L and Waters M 2014 Chem. Sci. 53287

59. Le Roy J J, Ungur L, Korobkov I, Chibotaru L F and Murugesu M 2014 J. Am. Chem. Soc. 1368003

60. Guo Y-N, Ungur L, Granroth G E, Powell A K and Wu C 2014 Sci. Rep. 45471

61. Chibotaru L F 2014 In Theoretical Understanding of Anisotropy in Molecular Nanomagnets (Berlin Heidelberg: Springer) pp. 1-45

62. Venugopal A, Tuna F, Spaniol T P, Ungur L and Chibotaru L F 2013 Chem. Commun. 49901

63. Blagg R J, Ungur L, Tuna F, Speak J and Comar P 2013 Nat. Chem. 5673

64. Wang Y-X, Shi W, Li H, Song Y and Fang L 2012 Chem. Sci. 33366

65. Gendron F, Pritchard B, Bolvin H and Autschbach J 2015 Dalton Trans. 4419886

66. Gómez-Coca S, Aravena D, Morales R and Ruiz E 2015 Coord. Chem. Rev. 289379

67. Hänninen M M, Mota A J, Aravena D, Ruiz E and Sillanpää R 2014 Chem. Eur. J. 208410

68. Oyarzabal I, Ruiz J, Seco J M, Evangelisti M and Camón A 2014 Chem. Eur. J. 2014262

69. Gómez-Coca S, Urtizberea A, Cremades E, Alonso P J and Camón A 2014 Nat. Commun. 55300

70. Costes J P, Titos-Padilla S, Oyarzabal I, Gupta T and Duhayon C 2016 Inorg. Chem. 554428

71. Upadhyay A, Singh S K, Das C, Mondol R and Langley S K 2014 Chem. Commun. 508838

72. Singh S K, Gupta T and Rajaraman G 2014 Inorg. Chem. 5310835

73. Rajaraman G, Singh S K, Gupta T and Shanmugam M 2014 Chem. Commun. 501551

74. Gupta T and Rajaraman G 2014 J. Chem. Sci. 1261569

75. Lucaccini E, Sorace L, Perfetti M, Costes J-P and Sessoli R 2014 Chem. Commun. 501648

76. Costes J P, Titos-Padilla S, Oyarzabal I, Gupta T and Duhayon C 2015 Chem. Eur. J. 2115785

77. Das C, Vaidya S, Gupta T, Frost J M and Righi M 2015 Chem. Eur. J. 2115639

78. Singh S K, Gupta T, Ungur L and Rajaraman G 2015 Chem. Eur. J. 2113812

79. Meihaus K R, Minasian S G, Lukens W W, Kozimor S A and Shuh D K 2014 J. Am. Chem. Soc. 1366056

80. Aquilante F, Autschbach J, Carlson R K, Chibotaru L F and Delcey M G 2016 J. Comput. Chem. 37506
81. Aquilante F, De Vico L, Ferre N, Ghigo G and Malmqvist P A 2010 J. Comput. Chem. 31224

82. Duncan J A 2009 J. Am. Chem. Soc. 1312416

83. Swerts B, Chibotaru L F, Lindh R, Seijo L and Barandiaran Z 2008 J. Chem. Theory Comput. 4586

84. Veryazov V, Widmark P O, Serrano-Andres L, Lindh $\mathrm{R}$ and Roos B O 2004 Int. J. Quantum Chem. 100626

85. Karlstrom G, Lindh R, Malmqvist P A, Roos B O and Ryde U 2003 Comput. Mater. Sci. 28222

86. Malmqvist P A, Roos B O and Schimmelpfennig B 2002 Chem. Phys. Lett. 357230

87. Chibotaru L F and Ungur L 2012 J. Chem. Phys. 137 064112

88. Ungur L and Chibotaru L 2006 In The computer programs SINGLE_ANISO and POLY_ANISO (Leuven: University of Leuven)

89. Frisch M J, Trucks G W, Schlegel H B, Scuseria G E, Robb M A, Cheeseman J R, Scalmani G, Barone V, Mennucci B, Petersson G A, Nakatsuji H, Caricato M, Li X, ratchian H P, Izmaylov A F, Bloino J, Zheng G, Sonnenberg J L, Hada M, Ehara M, Toyota K, Fukuda R, Hasegawa J, Ishida M, Nakajima T, Honda Y, Kitao O, Nakai H, Vreven T, Montgomery J A Jr, Peralta J E, Ogliaro F, Bearpark M, Heyd J J, Brothers E, Kudin K N, Staroverov V N, Kobayashi R, Normand J, Raghavachari K, Rendell A, Burant J C, Iyengar S S, Tomasi J, Cossi M, Rega N, Millam N J, Klene M, Knox J E, Cross J B, Bakken V, Adamo C, Jaramillo J, Gomperts R, Stratmann R E, Yazyev O, Austin A J, Cammi R, Pomelli C, Ochterski J W, Martin R L, Morokuma K, Zakrzewski V G, Voth G A, Salvador P, Dannenberg J J, Dapprich S, Daniels A D, Farkas Ö, Foresman J B, Ortiz J V, Cioslowski J and Fox D J 2009 In Gaussian 09, Revision D.01 (Wallingford CT: Gaussian, Inc.)

90. Cundari T R and Stevens W J 1993 J. Chem. Phys. 98 5555

91. Schafer A, Huber C and Ahlrichs R 1994 J. Chem. Phys. 1005829

92. Becke A D 1993 J. Chem. Phys. 985648

93. Lee C, Yang W and Parr R G 1988 Phys. Rev. B. 37785

94. Stephens P J, Devlin F J, Chabalowski C F and Frisch M J 1994 J. Phys. Chem. 9811623

95. Bader R F W 1990 In Atoms in molecules-A Quantum Theory (Oxford, UK: Oxford University Press)

96. Bader R F W 2009 J. Phys. Chem. A 11310391

97. BieglerKönig F and Schönbohm J 2002 J. Comput. Chem. 231489

98. Chilton N F, Collison D, McInnes E J L, Winpenny R E P and Soncini A 2013 Nat. Commun. 42551

99. Espinosa E, Alkorta I, Elguero J and Molins E 2002 J. Chem. Phys. 1175529

100. Jenkins S and Morrison I 2000 Chem. Phys. Lett. 31797

101. Jabłonński M 2015 J. Phys. Chem. A 11911384

102. Jabłoński M 2015 J. Phys. Chem. A 1194993

103. Popelier P and Logothetis G 1998 J. Organomet. Chem. 555101

104. Tognetti V, Joubert L, Raucoules R, De Bruin T and Adamo C 2012 J. Phys. Chem. A 1165472 